\title{
Performance evaluation of a submerged tidal energy device with a single mooring line
}

Bin Guo ${ }^{1}$, Dazheng Wang ${ }^{1}$, Junwei Zhou ${ }^{1}$, Weichao Shi $^{2}$, Xu Zhou ${ }^{1 *}$,

1 School of Naval Architecture and Ocean Engineering, Harbin Institute of Technology, Weihai, PR China

2 Department of Naval Architecture, Ocean and Marine Engineering, Strathclyde University, United Kingdom

Corresponding Author:

Mr. Xu Zhou, zhouxu_andy@yeah.net

Naval Architecture and Ocean Engineering

Harbin Institute of Technology, Weihai, PR China

Office Phone: +86-15263120128 


\section{Nomenclature}

$A_{T}$ is the swept area of the turbine

$C_{P}$ is the power coefficient of the DATT

$C_{\mathrm{d}}$ is the drag coefficient of the DATT

$D_{C}$ is the drag force of cross tail

$D_{F}$ is the drag force of the buoyancy body

$D_{T}$ is the total drag force of contra-rotating DATTs

$D_{T 1}$ is the horizontal force generated by the left DATT

$D_{T 2}$ is the horizontal force generated by the right DATT

$F_{B}$ is the buoyancy force of the device

$F_{G}$ is the gravity force of the device

$F_{M}$ is the tension force of the mooring line

$F_{M(X)}$ is the $\mathrm{X}$ components of the tension force of the mooring line $F_{M(Y)}$ is the $\mathrm{Y}$ components of the tension force of the mooring line $F_{M(Z)}$ is the $Z$ components of the tension force of the mooring line $L_{C}$ is the lift force generated by the cross tail

$L_{F}$ is the vertical force generated by the buoyancy body

$L_{T}$ is the total vertical force generated

by contra-rotating DATTs

$L_{T 1}$ is the vertical force generated by the left DATT

$L_{T 2}$ is the vertical force generated by the right DATT

$l_{1}$ is the vertical distance from the connection point to the buoyancy body's hydrodynamic centre

$l_{2}$ is the vertical distance from the connection point to the DATT's hydrodynamic centre

$l_{3}$ is the horizontal distance from connection point to cross tail's hydrodynamic centre

$l_{4}$ is the vertical distance from connection point to the cross tail's hydrodynamic centre

$l_{5}$ is the horizontal distance from connection point to the centre of buoyancy

$l_{6}$ is the horizontal distance from connection point to the centre of gravity,

$l_{7}$ is the horizontal distance from 
connection point to the buoyancy body's hydrodynamic centre

$l_{8}$ is the horizontal distance from connection point to the DATT's hydrodynamic centre

$l_{9}$ is the horizontal distances from the connection point to the right DATT's hydrodynamic centre

$l_{10}$ is the horizontal distances from the connection point to the left DATT's hydrodynamic centre $l_{11}$ is the vertical distance from the connection point to the right DATT's hydrodynamic centre $l_{12}$ is the vertical distance from the connection point to the left DATT's hydrodynamic centre

$l_{13}$ is the vertical distance from the connection point to the buoyancy body's hydrodynamic centre $M_{Y}$ is the righting moment about the $Y$ axial at the connection point

$\lambda$ is the tip speed ratio of the turbine

$\omega$ is the angular velocity of the turbine

$\mathrm{R}$ is the radius of the rotor

$V$ is the incoming velocity

$P$ is the output power of the DATT $\rho$ is the density of seawater

$Q$ is the torque of the turbine $u_{i}$ is the time averaged velocity components in Cartesian coordinates $u_{i}^{\prime}$ is the fluctuating velocity components in Cartesian coordinates $P_{t}$ is the time averaged pressure $\mu$ is the viscous coefficient $-\rho \overline{u_{i}^{\prime} u_{j}^{\prime}}$ is the Reynolds stress tensor 
Abstract: A submerged tidal energy device with contra-rotating Diffuser Augmented Tidal Turbines (DATTs) has been investigated in this paper. The device is moored to the seabed with a single mooring line, which limit it to operate at mean water depth, but otherwise allows it to float freely with the tidal current, like a kite in the wind, to harness tidal current energy. This research focuses on the evaluation of stability and power generation of the submerged tidal energy device based on $1: 5^{\text {th }}$ scaled model tests and the full-scaled prototype sea trials.

A 1:5 ${ }^{\text {th }}$ scaled model had been manufactured and tested in a circulating water channel to observe the power generation performance and working attitude around the designed inflow velocity. A full-scaled prototype was manufactured and tested near the CHU Island in Shandong Province, China. The results show that the device can change its direction automatically to make the DATTs face the tidal inflow, as the tidal current changes direction. The device has a good stability in pitch and roll motions. But the device's stability in yaw motions is worse than the other two, which will significantly affect the power generation performance and introduce more demanding structural requirements.

Keywords: Contra-Rotating; Diffuser-Augmented Tidal Turbine (DATT); Submerged Tidal Energy Device; Model Tests; Full-Scaled Prototype; Single Mooring Line 


\section{Introduction}

The Ocean, covering more than $70 \%$ of the earth, has long been appreciated as a potential source of limitless renewable energy. Tidal current energy draws more renewable energy developers' attention as it can provide relatively more regular and predictable energy output than other sources of renewable energy (Bahaj A. S et al., 2007; Batten W. M. Jet al.,2007); What more, seawater is more than 800 times denser than air as a medium for energy transfer, thus making tidal current turbines more manageable in size compared the wind turbines(Ben Elghali et al., 2007; Charlier, R.H., 2003).

Even though the tidal current energy has a number of advantages, the costs of installation and maintenance for tidal energy devices are very high. In the ocean environment, installation and maintenance costs increase significantly due to the limited accessibility of the site and specialist equipment and expertise required for underwater works. Also, treatment for corrosion and biofouling in sea water will add additional costs compared to that of land wind turbines (Ben Elghali et al., 2007; Pelc and Fujita, 2002).

Various types of horizontal axis tidal energy devices have been developed in past years. Most devices can be divided into three types in terms of support structure. These are: gravity structure devices, piled structure devices and floating structure devices. Gravity structure devices, such as the Open-Center turbine (Baker, N. J et al. 2014), suffer from high maintenance costs and the lower current velocity due to their proximity to the sea bed. Piled structure devices, such as SeaGen (Douglas, C.Aet al., $\underline{2008)}$, are characterized by high installation and maintenance costs as well as by interference with navigation. Floating structure devices, such as the Scotrenewables Tidal Turbine (SRTT) (Francis and Hamilton, 2007), are easily affected by wind, waves and other external environmental factors, especially so by strong weather systems like typhoons and hurricanes.

Reducing the costs of installation and maintenance is the key issue for the practical use of marine renewable energy. Therefore, tidal energy devices with lower installation and maintenance costs and higher safety margins have been developed. 
These devices work beneath the water surface to avoid any potential damage caused by waves and wind; it is moored to the seabed for easy installation and maintenance. Such as GEM-Ocean's Kite (Coiro,D. P et al., 2013) which is an innovative, submerged tidal current energy converter with two contra-rotating turbines; And a floating ocean-current device for use in Kuroshio currents (Shirasawa et al., 2016) with a single turbine.

Based on the situation of low tidal current velocity near China (Liu, H. W et al., 2011), a submerged tidal energy device with contra-rotating DATTs is presented in this paper. The average velocity over a year in sea trial site is close to $1 \mathrm{~m} / \mathrm{s}$. Therefore, the designed tidal current velocity in this paper was determined as $1 \mathrm{~m} / \mathrm{s}$. The device belongs to the submersible floating structure device type, and it tries to overcome the problems mentioned above that are typical of the other device types. The device operates at mean sea depth and is moored to the sea bottom by a gravity base with a single mooring line, as shown in Fig.1. The device is designed to provide the electrical energy for small instruments used in marine environmental monitoring. It works near the instruments and can provide electricity continuously.

Considering the working mode of the device, like kites in the tidal current, the connection point position is very important to the stability of the device. The connection point position is determined by the drag forces of the DATTs and the buoyancy body. Prior work, carried out by Shi et al., 2015, initially investigated the hydrodynamic performance of the DATT. Therefore, the numerical simulations presented in this paper are carried out only for evaluating the drag forces of the buoyancy body. The shape of the buoyancy body is similar to that of a submarine. The numerical simulation method for the buoyancy body drag forces can draw experiences from that of the submarine. Tyagi, A et al, 2006 investigated the transverse hydrodynamic coefficients of two typical Autonomous Underwater Vehicles (AUV) based on CFD solver. Pan et al, 2012 explored the submarine hydrodynamic coefficients using CFD simulation, and studied the influence of the $y+$ value on the accuracy of the numerical prediction.

This research focuses on the evaluation of stability and power generation of the 
submerged tidal energy device. The structure of this paper is as follows. First, the drag forces of the DATTs and the buoyancy body are evaluated for determining the connection point position. Second, the $1: 5^{\text {th }}$ scaled model was manufactured and tested in the circulating water channel of Harbin Institute of Technology (HIT) to observe the power generation performance and the device working attitude relative to the connection point. Finally, the full-scaled prototype was manufactured and tested in the open sea water near CHU Island in Shandong Province, China.

\section{Design concept and configuration of the device}

The submerged tidal energy device is designed for low installation and maintenance costs. This device consists of five major components: (1) the contra-rotating DATTs, (2) the connecting plate frame, (3) the buoyancy body with cross tail, (4) the gravity base, and (5) the single mooring line. The position where the mooring line is connected with the connecting plate frame is named the connection point. The basic structure of this tidal energy device is shown in Fig.2.

The device has no impact on navigation and is not affected by wind, waves and other external surface environmental factors. The installation and recovery of the device are realized by injecting seawater into the gravity base which is of a hollow steel frame structure with a submersible pump being installed inside, and draining seawater from the gravity base, respectively, for low installation and maintenance costs as well as fast deployment operations.

In Fig.2, It can be seen that a pair of contra-rotating DATTs sit aside of the buoyancy body, and they are connected to the buoyancy body with a connecting plate frame. A diffuser is placed around each turbine to increase the velocity of water flow through the turbine swept area (Bussel, 2007; Burton et al., 2011; Harrison et al., 2010). Nacelle houses a $1: 7.5^{\text {th }}$ gearbox, an electrical clutch and a permanent magnet generator, as shown in Fig.3. Each generator is electrically controlled by a controller to maximize the power generation performance at varied current velocities. In this paper, a clutch is installed between the turbine rotor and the generator in order to lower the cut-in velocity. While the inflow velocity is lower than the cut-in velocity, 
the clutch disconnects the turbine from the generator so that the turbine rotor can rotate freely with minimum load and inertia; once the inflow velocity reaches the cut-in velocity, the clutch will connect the turbine rotor to the generator to harness the current energy. With the aid of this system, the cut-in velocity can be lowered to $0.5 \mathrm{~m} / \mathrm{s}$

A cross tail is installed at the tail of the buoyancy body to provide the righting movement when roll, pitch or yaw occurs. The buoyancy body is located the top of the device, which makes the centre of buoyancy higher than the centre of gravity to enhance the stability of the device in the roll and pitch motions. The dimensional parameters of the full-scaled prototype are given in Table.1.

\section{Forces acting on the device and their equilibrium}

In calm water states, the primary forces acting on the submerged tidal current device are the buoyancy force, the gravitational force and the tension force of the mooring line. The device is subject to additional forces along the tidal current direction when a tidal current flows by, such as the drag force of the DATTs, the drag force of the buoyancy body and the cross tail. Some extra forces, such as the lift forces generated by the buoyancy body and the cross tail, will act on the device when the roll, pitch or yaw movements occurs, and these forces can help the device return to an equilibrium condition.

The forces acting on the submerged tidal current device are relatively complicated. In order to simplify the equation, some physical adjustments and assumptions are made as follows: (1) The centre of gravity has been adjusted to the same vertical line with the centre of buoyancy by adding counterweights in the buoyancy body, as shown in Fig.3. (2) The contra-rotating turbines can cancel undesirable reactive torque formed by rotation of the turbine (Finkl, C. W et al., 2009; Sakata et al., 2012; Vanzwieten,J et al., 2006), as such, reactive torque is not considered in this paper. (3) The effects of interaction between adjacent bodies (interference effects) are disregarded.

In this paper, the forces acting on the device will be analyzed in the following three 
conditions. The first one is that the turbines' axes of the device are in line with the tidal current direction (in the following, named as inline current). The second one is that the turbines' axes have a pitch angle with tidal current direction (named as pitch angle current). The third one is that the turbine's axes have a yaw angle with current direction (named as yaw angle current).

\subsection{Forces acting on the device with inline current}

The inline current condition can only be achieved at the designed tidal current velocity with the connection point being carefully arranged, so that the turbines' axes should be kept parallel to the tidal current direction that is also the horizontal direction in order to maximize energy capture, as shown in Fig.4, this is named as the equilibrium position in this paper. The primary forces acting on the device are also shown in Fig.4. In the following forces analysis, the $\mathrm{x}$ axis of the coordinate system is parallel to the horizontal direction, and the $y$ axis is parallel to the vertical direction.

The forces and moments acting on the device in the $\mathrm{x}$ and $\mathrm{y}$ directions should meet following equations in order to make the device maintain equilibrium position:

$$
\begin{gathered}
F_{M(X)}=D_{F}+D_{T}+D_{C} \\
F_{M(Y)}=F_{B}-F_{G} \\
\left(D_{F}+D_{C}\right) * l_{1}=D_{T} * l_{2}
\end{gathered}
$$

Where $D_{F}$ is the drag force of the buoyancy body, $\mathrm{N} ; D_{T}$ is the drag force of contra-rotating DATTs, N; $D_{C}$ is the drag force of the cross tail, N; $F_{M(X)}$ and $F_{M(Y)}$ are the $\mathrm{X}$ and $\mathrm{Y}$ components of the tension force of the mooring line $\left(F_{M}\right)$, respectively, $\mathrm{N} ; F_{G}$ and $F_{B}$ are the gravity and buoyancy forces of the device, respectively, $\mathrm{N} ; l_{1}$ is the vertical distance from the connection point to the buoyancy body's hydrodynamic centre, $\mathrm{m} ; l_{2}$ is the vertical distance from connection point to the DATT's hydrodynamic centre, $\mathrm{m}$. 
The exact position of connection point (i.e. values of $l_{1}$ and $l_{2}$ ) will be determined by the drag forces of buoyancy body, cross tail and contra-rotating DATTs at the designed tidal current velocity, as shown in Equation (3), and it will be described later in section 4.

\subsection{Forces acting on the device with pitch angle current}

The drag forces of the buoyancy body, the cross tail and the contra-rotating DATTS will change at other tidal current velocities, so that the device will not be at equilibrium relative to the connection point under this condition, and will produce a pitch angle, as shown in Fig.5.

The forces and moments acting on the device in the $\mathrm{x}$ and $\mathrm{y}$ directions, at other tidal current velocities, should meet following equations in order to allow the device to maintain equilibrium:

$$
\begin{gathered}
F_{M(X)}=D_{F}+D_{T}+D_{C} \\
F_{M(Y)}=F_{B}+L_{C}+L_{F}+L_{T}-F_{G} \\
F_{B} * l_{5}+F_{G} * l_{6}+L_{C} * l_{3}+L_{F} * l_{7}+D_{T} * l_{2}+L_{T} * l_{8}=D_{F} * l_{1}+D_{C} * l_{4}
\end{gathered}
$$

Where $L_{C}$ is the lift force generated by the cross tail, $\mathrm{N} ; L_{F}$ is the vertical force generated by the buoyancy body, $\mathrm{N} ; L_{T}$ is the vertical force generated by the contra-rotating DATTs, $\mathrm{N} ; l_{3}$ is the horizontal distance from the connection point to the cross tail hydrodynamic centre, $\mathrm{m} ; l_{4}$ is the vertical distance from the connection point to the cross tail hydrodynamic centre, $\mathrm{m}$; $l_{5}$ is the horizontal distance from the connection point to the centre of buoyancy, $m ; l_{6}$ is the horizontal distance from the connection point to the centre of gravity, $\mathrm{m} ; l_{7}$ is the horizontal distance from the connection point to the buoyancy body hydrodynamic centre, $\mathrm{m} ; l_{8}$ is the horizontal distance from the connection point to the DATT's hydrodynamic centre, $\mathrm{m}$. 
As shown in Equation (6), it can be seen that the cross tail which is installed at the end of buoyancy body provides a righting moment to allow the device to maintain equilibrium when pitch motion occurs. What's more, the righting movement generated by the buoyancy force and gravity force further enhances the stability of the device in the pitch motion.

\subsection{Forces acting on the device with yaw angle current}

When the working conditions of the two DATTs are different, the turbines' axes will have a yaw angle with the tidal current direction as shown in Fig.6. The forces and moments acting on the device in the $x$ and $z$ directions, in this condition, should meet following equations:

$$
\begin{gathered}
F_{M(X)}=D_{F}+D_{T 1}+D_{T 2}+D_{C} \\
F_{M(Z)}=L_{C}+L_{F}+L_{T 1}+L_{T 2} \\
M_{Y}=L_{C} * l_{3}+D_{C} * l_{4}+L_{T 1} * l_{10}+D_{T 1} * l_{12}+L_{T 2} * l_{9}-D_{T 2} * l_{11}+L_{F} * l_{7}+D_{F} * l_{13}
\end{gathered}
$$

Where $L_{T 1}$ and $L_{T 2}$ are the vertical forces generated by the contra-rotating DATTs, $\mathrm{N} ; D_{T 1}$ and $D_{T 2}$ are the horizontal forces generated by the contra-rotating DATTs, $\mathrm{N} ; F_{M(X)}$ and $F_{M(Z)}$ are the $\mathrm{X}$ and $\mathrm{Z}$ components of the tension force of the mooring line $\left(F_{M}\right)$, respectively, $\mathrm{N} ; l_{9}$ and $l_{10}$ are the horizontal distances from the connection point to the DATT's hydrodynamic centre, respectively, $\mathrm{m} ; l_{11}$ and $l_{12}$ are the vertical distance from the connection point to the DATT's hydrodynamic centre, respectively, $\mathrm{m} ; l_{13}$ is the vertical distance from the connection point to the buoyancy body's hydrodynamic centre, $\mathrm{m} ; M_{Y}$ is the righting moment about the $\mathrm{Y}$ axial at the connection point, $\mathrm{Nm}$.

As shown in Equation (9), it can be seen that the cross tail, the buoyancy body and the DATTs can provide a righting movement to make the device consistent with the tidal current direction when the device works in yaw angle current. It seems to be 
that the device can adapt itself to face the tidal current direction. However, the righting movement generated by the buoyancy force and gravity force does not work in the yaw motion.

When the tidal current comes from downstream, a righting moment is generated by the cross tail, the buoyancy body and the DATTs, which is opposed to the righting moment in upstream condition, as shown in Fig.7. This righting movement causes the device to turn around, thus keeping the nose of the device facing the tidal current direction.

\section{The $1: 5^{\text {th }}$ scaled model tests}

As described in section 3.1.1, in order to maintain the equilibrium of the device at the designed tidal current velocity, it is very important to determine more accurately the drag forces of the contra-rotating DATTs and the buoyancy body, so as to determine the exact position of connection point. Therefore, the drag forces of the DATTs model and the buoyancy body model are first determined in this section. Then the connection point position can be calculated using the Equation (3). Finally, the $1: 5^{\text {th }}$ scaled model of the whole device was tested in the circulating water channel of HIT.

\subsection{The drag force of the $1: 5^{\text {th }}$ scaled DATT model}

In order to evaluate the drag force of the single DATT model, a 1:5 th scaled DATT model was manufactured and tested in the circulating water channel of HIT, as shown in Fig.8. The tests initially investigated the hydrodynamic performance of the 1:5 $5^{\text {th }}$ scaled DATT model. The detailed results were given in Shi et al., 2015, and it will not be described in details in this paper. Only the main hydrodynamic performance of DATT model is shown in Fig.9-10.

To evaluate the performance of the DATT model, the corresponding equations are given as follows:

$$
\lambda=\frac{\omega \mathrm{R}}{V}
$$




$$
\begin{aligned}
& C_{P}=\frac{P}{\frac{1}{2} \rho V^{3} A_{T}}=\frac{Q^{*} \omega}{\frac{1}{2} \rho V^{3} A_{T}} \\
& C_{\mathrm{d}}=\frac{D_{T}}{\frac{1}{2} \rho V^{2} A_{T}}
\end{aligned}
$$

Where $\lambda$ is the tip speed ratio of the turbine; $\omega$ is the angular velocity of the turbine, $\mathrm{rad} / \mathrm{s} ; \mathrm{R}$ is the radius of the rotor, $\mathrm{m} ; \quad V$ is the incoming velocity, $\mathrm{m} / \mathrm{s} ; P$ is the output power of the DATT, $\mathrm{W} ; \rho$ is the density of seawater, $\mathrm{kg} / \mathrm{m}^{3} ; A_{T}$ is the swept area of the turbine, $\mathrm{m}^{2} ; Q$ is the torque of the turbine, $\mathrm{Nm} ; D_{T}$ is the drag force of the DATT, N.

Fig.9 shows that the power coefficient $(C p)$ of the $1: 5^{\text {th }}$ scaled DATT model in a range of tip speed ratio. The maximum power coefficient is approximately $69.6 \%$ at $\lambda=6.5$. Fig.10 shows the drag coefficients $\left(C_{d}\right)$ of the $1: 5^{\text {th }}$ scaled DATT model. The drag coefficient $\left(C_{d}\right)$ is approximately 3.18 at $\lambda=6.5$ which will be used to calculate the drag force of the DATT prototype.

\subsection{The drag force of the $1: 5^{\text {th }}$ scaled buoyancy body model}

\subsubsection{Governing equations}

Numerical simulations for the $1: 5^{\text {th }}$ scaled buoyancy body model was performed with the CFD software STAR-CCM+. Water density was $997.56 \mathrm{~kg} / \mathrm{m}^{3}$ and the dynamic viscosity was $0.889 \times 10-{ }^{3} \mathrm{~Pa}$.s. The flow around the buoyancy body model is modeled using the incompressible, Reynolds-Averaged Navier-Stokes (RANS) equations.

$$
\begin{aligned}
& \frac{\partial\left(u_{i}\right)}{\partial x_{i}}=0 \\
& \frac{\partial\left(\rho u_{i}\right)}{\partial t}+\rho u_{j} \frac{\partial\left(u_{i}\right)}{\partial x_{j}}=\rho F_{i}-\frac{\partial P_{t}}{\partial x_{i}}+\frac{\partial}{\partial x_{j}}\left[\mu \frac{\partial\left(u_{i}\right)}{\partial x_{j}}-\rho \overline{u_{i}^{\prime} u_{j}^{\prime}}\right]
\end{aligned}
$$

Where $u_{i}$ is the time averaged velocity components in Cartesian coordinates $x_{i}$ $(\mathrm{i}=1,2,3), \mathrm{m} / \mathrm{s} ; F_{i}$ is the buoyancy body forces, $\mathrm{N} ; \rho$ is the fluid density, $\mathrm{kg} / \mathrm{m}^{3}$; 
$P_{t}$ is the time averaged pressure, $\mathrm{Pa} ; \mu$ is the viscous coefficient; $u_{i}^{\prime}$ is the fluctuating velocity components in Cartesian coordinates, $\mathrm{m} / \mathrm{s} ;-\rho \overline{u_{i}^{\prime} u_{j}^{\prime}}$ is the Reynolds stress tensor, $\mathrm{N}$.

The finite volume method (FVM) is employed to discretize the governing equations with the second-order upwind scheme. The Semi-Implicit Method for the Pressure-Linked Equations (SIMPLE) is used for the pressure-velocity coupling. In order to allow closure of the time averaged Navier-Stokes equations, industrially acknowledged and recommended K- $\omega$ Shear Stress Transport (K- $\omega$ SST) turbulence model is adopted in this paper.

\subsubsection{Boundary conditions}

The computational domain of the buoyancy body model is a cylinder-shaped domain. The total length of the buoyancy body model $(L)$ is defined as the reference length to describe the domain size. The velocity-inlet boundary is positioned $5 \mathrm{~L}$ upstream of the buoyancy body model with an inflow velocity of $1 \mathrm{~m} / \mathrm{s}$, and the pressure-outlet boundary defined at $10 \mathrm{~L}$ downstream. Velocity-inlet boundary is also applied to the shroud of the cylinder-shaped domain. The radius of the cylinder-shaped domain is 3L. No-slip wall boundary condition is applied to the buoyancy body model. The boundary conditions of the numerical simulation are shown in Fig.11.

\subsubsection{Mesh generation}

Automatic meshing tool is used to generate the mesh for the buoyancy body model. Some feature curves, such as the leading and tailing edges of the cross tail, are marked to capture the shape of the model. A curve control is created to make sure that the flow characteristics around the model can be adequately captured.

The $y+$ value, the thickness of the first cells adjacent the buoyancy body model, is related with the accuracy of the numerical prediction. In this paper, referring to the work of the Pan et al, the selection range of $y+$ value is 30 to 60 . The surface mesh of the $1: 5^{\text {th }}$ scaled buoyancy body model is shown in Fig.12. 


\subsubsection{Mesh independence study}

Before the CFD analysis, the sensitivity of the solution to the resolution of the grid should be determined. Three different sets of grids named Grid 1, Grid 2 and Grid 3 are used in STAR-CCM+ to check the mesh independence of the results. With the limited computational resource, in the computational domain the grid is refined with a ratio of $\sqrt{2}$ in three directions: the longitudinal, the transversal and the normal directions. The cells contained in the computational grids increased from $2.80 * 10^{6}$ cells for the coarse grid to $1.31 * 10^{7}$ cells for the fine grid.

The $y+$ value is related to the accuracy of the numerical prediction. In this paper, the $y+$ value varies from 30 for the fine grid to 60 for the coarse grid. The mesh convergence test is carried out focusing on the drag force of the buoyancy body model, the CFD results are listed in Table.2. It can be seen that the results do not change significantly from the fine grid to the coarse grid. To maintain grid-resolution consistency for different cases and also to balance the accuracy and the computational cost, the medium grid of Grid 2 is adopted for the following computation.

\subsubsection{Validation of numerical simulation}

In order to verify the accuracy of numerical simulation results, a structure similar to the existing buoyancy body model is tested in the circulating water channel of HIT. The model test set up is given in Fig.13 and Shi et al., 2015, the results of the CFD and model tests are given in Fig.14, from which it can be seen that the CFD results agree well with the experimental data.

Fig.15 shows the predicted drag force of the $1: 5^{\text {th }}$ scaled buoyancy body model $D_{F}+D_{C}$ (including the drag force of cross tail), from which, the drag force of the $1: 5^{\text {th }}$ scaled buoyancy body model is approximately $8.7276 \mathrm{~N}$ at the designed tidal current velocity of $1 \mathrm{~m} / \mathrm{s}$.

\subsubsection{The connection point position}


As stated in Section 4.1, the drag coefficient $\left(C_{d}\right)$ of DATT model at $\lambda=6.5$ is approximately 3.18. The drag force of the single DATT model is approximately $112 \mathrm{~N}$ at the designed tidal current velocity of $1 \mathrm{~m} / \mathrm{s}$. By substituting the above drag forces of $D_{T}$ and $D_{F}+D_{C}$ into Equation (3), the vertical distance from the shaft of the DATTS model to the connection point, i.e., $I_{2}$ in Equation (3) can be calculated, which is approximately $13.01 \mathrm{~mm}$ for the $1: 5^{\text {th }}$ scaled model, as the vertical distance $\left(I_{1}+I_{2}\right)$ from the centre of gravity to the hydrodynamic centre of the buoyancy body and cross tail is already known when the present device is set.

Following the same procedure, the drag force of the buoyancy body prototype $D_{F}+D_{C}$ is $229.82 \mathrm{~N}$ at the designed tidal current velocity of $1 \mathrm{~m} / \mathrm{s}$. According to the law of similarity and equation (9), the drag force of the DATT prototype $D_{T}$, can be calculated, which is approximately $2878.5 \mathrm{~N}$ at the designed tidal current velocity of $1 \mathrm{~m} / \mathrm{s}$. Therefore, the vertical distance from the shaft of DATTs to the connection point, i.e., $I_{2}$ is approximately $66.5 \mathrm{~mm}$ for the full-scaled prototype.

\subsection{Model tests}

Due to the critical effect of the connection point on the device equilibrium attitude, a $1: 5^{\text {th }}$ scaled device model was manufactured as shown in Fig.16 and tested in the circulating water channel of HIT to verify the connection position of the mooring line which is determined in the above section 4.2.6. Due to the limited measuring section size of the circulating water channel and the relatively large device model, model tests can only validate the equilibrium attitude of the device relative to the connection point, but not whole mooring line. The real operating performance of the device will be tested in sea trials.

\subsubsection{Model test set-up}

The model tests were carried out in the circulating water channel of Harbin Institute of Technology (HIT), Weihai. The test section of the circulating water channel is shown in Fig.17, and the test section particulars are presented in Table.3.

An attitude sensor (AH100B) was installed in the buoyancy body model to capture 
the working attitude of the device, as shown in Fig.18. The definition of the rotation axis is shown in Fig.19. The measurement accuracy and resolution in yaw, pitch and roll motions are given in Table.4.

In this paper, a commercial turbine controller, MAX-T2-WI-NNHH-2, was adopted which used the hill climbing method to search the maximum power generation of the DATT model at different inflow velocities, as shown in Fig.20. The turbine controller can also receive $A C$ signals outputted by the generators and convert the $A C$ signals into DC signals.

The $1: 5^{\text {th }}$ scaled device model was installed in the middle of the circulating water channel and tethered to the bottom by a single mooring line. The model in calm water and its measured attitude is shown in Fig.21. It shows that the pitch, roll and yaw angles of the model are $-0.3^{\circ},-1.8^{\circ}$ and $0.9^{\circ}$, respectively. This attitude is named the original position in this paper.

\subsubsection{Model test results and analysis}

The designed inflow velocity is $1 \mathrm{~m} / \mathrm{s}$. The model tests were carried out at $0.89 \mathrm{~m} / \mathrm{s}$, $0.95 \mathrm{~m} / \mathrm{s}$ and $1.01 \mathrm{~m} / \mathrm{s}$ to evaluate the stability and power generation performance of the device model. Results of the model tests are given in Fig.22 and Table.5-6.

Fig. 22 shows the power generation performance of the model, including the turbine rotational speed, generator output voltage and current at above stated inflow velocities. It can be seen that there is no significantly difference between the power generation performances of the two DATTs.

The average output power is shown in Table.5, and compared to the stand alone DATT model unit given in Shi et al., 2015. It can be seen that the turbine controller can make the DATTs work around the designed tip speed ratio at varying inflow velocities. At the designed inflow velocity of $1 \mathrm{~m} / \mathrm{s}$, the power coefficients were $66.45 \%$ at $\lambda=6.49$ for the left DATT model and $65.05 \%$ at $\lambda=6.51$ for the right DATT model, respectively, compared to the stand alone DATT model unit $69.6 \%$ at $\lambda=6.45$. Table.6 displays the average attitude value of this model at the above stated inflow velocities. It can be seen that the pitch, roll and yaw angles increase as the inflow velocity increases. At the designed inflow velocity of $1 \mathrm{~m} / \mathrm{s}$, the pitch, roll and yaw 
angles are approximately $-3.8^{\circ}, 3.8^{\circ}$ and $5.4^{\circ}$, respectively. Compared with the original position, the attitude of the device model changes little, and the maximum change of the angles is $4.5^{\circ}$. Therefore, it can be noticed that the $1: 5^{\text {th }}$ scaled device model can keep equilibrium relative to the connection point. It can further certify that the accuracy of the numerical simulation for the buoyancy body drag force is acceptable.

Based on the model tests results, the $1: 5^{\text {th }}$ scaled device model can keep equilibrium relative to the connection point. Due to the limited measuring section size of the circulating water channel and the relatively large device model, model tests can only validate the equilibrium attitude of the device relative to the connection point, but not whole mooring line. The real operating performance of the device will be tested in sea trials.

\section{Full-scaled prototype tests}

Limited by the size of the circulating water channel, the working attitude of the device cannot be completely and accurately presented by model tests, especially when the tidal current direction changes. Therefore, a full-scaled prototype was manufactured and tested in the open sea near the CHU Island in Shandong Province, China.

\subsection{Site Selection of the sea trial tests}

$\mathrm{CHU}$ Island is located in the northeast side of Weihai, as shown in Fig.23. There is an underwater trench to the north of the island, with a width and length of $500 \mathrm{~m}$ and $2500 \mathrm{~m}$, respectively. The water depth in most areas is more than 60 meters, with maximum depths of up to 70 meters. Due to the existence of trench, the tidal current velocity in this location is higher than that in other locations. The bathymetric map of the northern $\mathrm{CHU}$ Island is shown in Fig.24. In this figure, there are rocks and reefs in the red area, and the terrain in the blue areas are relatively flat. Considering the velocity in both blue areas, the sea trial site was chosen at 122.082 degrees East longitude and 37.5745 degrees North latitude, as indicated by the green dot in 
Fig. 24. The average velocity in the sea trial site is approximately $1 \mathrm{~m} / \mathrm{s}$.

\subsection{Control system of the device prototype}

The control system consists of the following parts: the data acquisition subsystem, the turbine control subsystem, the data transmission subsystem and the PC monitoring subsystem. The control system wiring diagram is shown in Fig. 25.

The data acquisition subsystem is divided into two parts: the underwater control module and the land control module. The latter is placed in the control centre on the $\mathrm{CHU}$ Island. The underwater control module is placed in the buoyancy body which is used to collect real-time experimental data, including generator rotational speed, output voltage and current, and inflow velocity, etc., as shown in Fig.26. Given the long distant between the control centre and the sea trial site, RS-485 and CAN BUS is selected to transfer the experimental data.

\subsection{Instrumentation and Calibration}

\subsubsection{Velocity sensor}

Considering the presence of sediment and organisms in seawater, a propeller-type velocity sensor was installed on buoyancy body. The parameters of this velocity sensor are given in Table.7.

In order to evaluate the accuracy of the velocity sensor, it was tested in the circulating water channel. The velocity measured by the propeller-type velocity sensor was compared to that measured by a pitot tube, results are shown in Fig.27. It can be seen that the differences between the two velocities are very small, therefore the propeller-type velocity sensor met the use requirements in this project.

As shown in section 3 , since the device can orient itself to the tidal current direction, no tidal current direction measuring sensor was installed on the device.

\subsubsection{On-shore tests}

The purpose of the on-shore tests was to determine the efficiency of the generator and test the accuracy of the turbine controller. During the on-shore tests, a motor 
was used to replace the turbine to drive the generator, as shown in Fig.28. And a dynamometer was installed between the motor and the generator to measure the torque and rotational speed of generator, from which, the input power can be calculated. The generator output power was measured by the turbine controller and three-phase meter. The three-phase meter was utilized to evaluate the accuracy of the turbine controller.

Results of the on-shore tests are given in Fig.29-30. Fig.29 shows the output power measured by the turbine controller and three-phase meter. It can be seen that the data from the turbine controller agrees well with the data from the three-phase meter. The measurement error, at the designed generator speed of $462 \mathrm{rpm}$, is approximately $3.94 \%$ for the left generator and $2.38 \%$ for the right generator, respectively.

Fig. 30 shows the efficiency of two generators. It shows that the efficiency of these two generators is very close, which is approximately $60.63 \%$ for the left generator and $60.16 \%$ for the right generator at the designed generator speed of $462 \mathrm{rpm}$.

\subsection{Sea trial testing conditions and measurement}

The submerged tidal current device was assembled at Xiaoshidao Wharf, as shown in Fig.31. Two 12V 100 Ah batteries were installed inside the buoyancy body to provide the electric energy for the control system and the clutches, as well as to store output power generated by the generator. The sea trial was carried out for three days, the two $12 \mathrm{~V} 100$ Ah batteries were exhausted, the output power of the generators was not sufficient to recharge the batteries.

It is very regrettable that the propeller-type velocity sensor was damaged during the device installation process. The research group subsequently made some remedial works to measure the tidal current velocity of the sea trial site in July, as shown in Fig.32. The measured tidal current velocity was used as a reference data to roughly evaluate the power generation performance of the device.

\subsection{Sea trial testing results and discussions}


The sea trial test results of the full-scaled device are presented in this section. In order to clearly analyse the results of sea trial tests, this section is divided into two parts, one is the power generation of the full-scaled device, and the other is the full-scaled device attitude.

\subsubsection{Power generation of the full-scaled device}

The output power of the full-scaled device was measured by the turbine controller during the sea trial. The maximum instantaneous power generation is $177 \mathrm{~W}$ for the right generator and $166 \mathrm{~W}$ for the left generator. The maximum tidal current velocity is approximately $0.969 \mathrm{~m} / \mathrm{s}$. By substituting the above power generation, tidal current velocity and the efficiency of these two generators into Equation (11), the power coefficient is $35.4 \%$ for the right DATT and $33.4 \%$ for the left DATT.

The average power generation results are shown in Table.8. The maximum average power generation during the sea trial occurred at night on the first day. The maximum average power generation of right generator is $32 \mathrm{~W}$, and the maximum average power generation of left generator is $70.61 \mathrm{~W}$. The average power generation is relatively small due to the low tidal current velocity and the low power generation efficiency of the generators.

In Table.8, the average power generation of the left generator is higher than the right one. The two generators are controlled by independent controllers. It is difficult to ensure the two generators work synchronously during the sea trials. What's more, the controllers use the hill climbing method to search the maximum power generation, that means the rotational speed of the generators can be changed freely, which may further increase the difference between the rotational speeds of the two turbines, resulting in inconsistent power generation of the two generators.

The above hypothesis is only based on the output data of the sea trial, and could not be verified as the prototype could not be retrieved for verification due to funding limitations.

\subsubsection{Working attitude of the full-scaled device}

The attitude sensor was installed in the buoyancy body of the full-scaled device. The 
output data of the attitude sensor is $0^{\circ}$ when the sensor points north, positive when rotating clockwise. The average attitude angles of the full-scaled device in the three days sea trial are shown in Table.9.

Table. 9 shows that the maximum change of the pitch angle and roll angle was no more than $4.55^{\circ}$, which illustrates that the full-scaled device has a good stability in these two motions. This phenomenon is more clearly seen in the real-time attitude data. As shown in Fig.33-34, the pitch angle and roll angle fluctuate slightly.

In the yaw motion, the device can change direction along with the tidal current. As shown in Table.9, on the first day morning, the device maintained a relatively stable state in the yaw motion; the yaw angle was around $138.86^{\circ}$. On the night of that day, the tidal current direction changed, and the yaw angle of the device changed to $-59.24^{\circ}$. A similar situation occurred in the following days, which shows that the device can adapt itself to the tidal current direction.

Comparing the real-time yaw angle of the device with other two angles in the pitch and roll motions, as shown in Fig.33, the fluctuations in yaw motions was larger than the other two. This situation may be caused by two factors. One is that the tidal current is unstable due to the dense reefs near the device location, as shown in Fig.24. The other is that because the power generations of the two generators are different, as described in section 5.5.1. The drag forces of the two DATTs are also different. This unbalanced drag force produces a movement which results in relatively larger yaw motions. By comparing Fig. 33 with Fig. 34 , it can be clearly seen that the influence of different power generation of the two generators on the yaw angle of the device. In Fig. 33 , the difference in power generation between the two generators is relatively large. The fluctuation amplitude in yaw motions is strongly. In Fig. 34, the difference in power generation between the two generators is relatively small. The fluctuation in yaw motions is smoothly.

Based on the sea trial tests results, the full-scaled device has a good stability in pitch and roll motions. In yaw motions, the full-scaled device can orient itself to face the tidal current direction. This feature can make the tidal current power generation device avoid using yaw mechanism or pitch mechanism. The installation and 22 / 43 
maintenance costs of the device can be further reduced. But the device's stability in yaw motions is worse than the other two, which will significantly affect the power generation performance and introduce more demanding structural requirements.

\section{Conclusions}

The research focuses on the evaluation of stability and power generation of the submerged tidal energy device based on $1: 5^{\text {th }}$ scaled model tests and the full-scaled prototype sea trials. With the study conducted in this paper, the following conclusions can be drawn:

1. The connection point position is determined by the drag forces of the DATTs and the buoyancy body in this paper. The working attitude results of the $1: 5^{\text {th }}$ scaled model tests verify the prediction accuracy of buoyancy body drag forces on one hand and the feasibility of connection point position selection on the other.

2. From the power generation and the working attitude results of the $1: 5^{\text {th }}$ scaled model tests, the device has a relatively good stability to support the contra-rotating DATTs working, although the influence of the wall effect is not considered.

3. The full-scale device sea trials seem to prove the feasibility and reliability of the system, especially for the case where tidal current velocity and water depth are limited.

4. From the results of full-scaled prototype sea trials, the full-scaled device has good stability in pitch and roll motions. In yaw motions, the full-scaled device can orient itself to face the tidal current direction, especially during the tidal current direction changes. But the device stability in yaw motions is worse than the other two, which will significantly affect the power generation performance and introduce more demanding structural requirements.

\section{Further work}

Due to the damage of the velocity sensor during the sea trial, the paper cannot 
comprehensively evaluate the power generation performance of the device. However, we can still learn some experience from a modelling and experimental point of view. First, the cross tail is a simple and effective method to improve the stability in yaw motions. In the design process of similar devices, the installation position and size of the cross tail should be comprehensively evaluated. Second, for small-scale application, special attention should be put on the energy requirement for maintaining the device's operation to make sure the device is self-sustainable. Third, special care should be taken on selection of the velocity sensor. An acoustic speed sensor (ADCP) will be installed on the device for more accurate sea trials.

\section{Acknowledgement}

The work presented in this paper is genuinely supported by State Oceanic Administration of People's Republic of China, grant GHME2011GD01 and the national natural science foundation of China, grant NO. U1706227. In the meantime, the authors would like to take this opportunity to express the gratitude to the support from the marine renewable energy team of Harbin Institute of Technology, Weihai. 


\section{Reference}

Bahaj A.S., Molland A.F., Chaplin J.R., 2007. Power and thrust measurements of marine current turbines under various hydrodynamic flow conditions in a cavitation tunnel and a towing tank [J]. Renew Energy, 32(3): 407-426.

Baker, N.J., Hodge, E., Cawthorne, S., \& Spooner, E., 2014. [institution of engineering and technology 7th iet international conference on power electronics, machines and drives (pemd 2014) - manchester, uk (8-10 april 2014)] 7th iet international conference on power electronics, machines and drives (pemd 2014) - modelling of the generator for openhydrol"s tidal energy system. 4.3.03-4.3.03.

Batten W.M.J., Bahaj A.S., Molland A.F., 2007. Experimentally validated numerical method for the hydrodynamic design of horizontal axis tidal turbines [J]. Ocean Engineering, 34(7): 1013-1020

Ben Elghali, S., Benbouzid, M., Charpentier, J.F., 2007. Marine tidal current electric power generation technology: State of the art and current status, Electric Machines \& Drives Conference, 2007. IEMDC'07.IEEE International. IEEE, pp. 1407-1412.

Burton, T., Jenkins, N., Sharpe, D., Bossanyi, E., 2011. Wind energy handbook. Wiley

Bussel, G.J.W.V., 2007. The science of making more torque from wind: Diffuser experiments and theory revisited: Journal of Physics: Conference Series.

Charlier, R.H., 2003. A "sleeper" awakes: tidal current power. Renewable and Sustainable Energy Reviews 7 (6), 515-529.

Coiro, D. P., Troise, G., Scherillo, F., Marco, A. D., \&Maisto, U., 2011. Experimental tests of GEM Ocean's kite, An innovative patented submerged system for marine current energy production. International Conference on Clean Electrical Power.IEEE.

Douglas, C.A., Harrison, G.P., Chick, J.P., 2008, Life cycle assessment of the Seagen marine current turbine, Proceedings of the Institution of Mechanical Engineers, Part M: Journal of Engineering for the Maritime Environment, 222 (M1), pp. 1-12

Finkl, C.W., Charlier, R., 2009. Electrical power generation from ocean currents in the straits of florida: some environmental considerations. Renewable and Sustainable Energy Reviews, 13(9), 2597-2604.

Francis, M., Hamilton, M., 2007. SRTT Floating Tidal Turbine Production Design Study with Independent Verification.

Harrison, M., Batten, W., Myers, L., Bahaj, A., 2010. Comparison between CFD simulations and experiments for predicting the far wake of horizontal axis tidal turbines. Renewable Power 
Generation, IET 4 (6), 613-627.

Liu, H. W., Ma, S., Li, W., 2011. A review on the development of tidal current energy in china. Renewable and Sustainable Energy Reviews, 15(2), 1141-1146.

Pan, Y. C., Zhang, H. X., \& Zhou, Q. D., 2012. Numerical prediction of submarine hydrodynamic coefficients using cfd simulation. Journal of Hydrodynamics, Ser. B, 24(6), 840-847.

Pelc, R., Fujita, R.M., 2002. Renewable energy from the ocean. Marine Policy 26 (6), 471-479.

Sakata, Gonoji, Takagi, 2012. A motion of twin type ocean current turbines in realistic situations. Oceans IEEE.

Shi, W., Wang, D., Atlar, M., Guo, B., \&Seo, K. C., 2015. Optimal design of a thin-wall diffuser for performance improvement of a tidal energy system for an auv. Ocean Engineering, 108, 1-9.

Shirasawa, Katsutoshi, 2016. Experimental verification of a floating ocean-current turbine with a single rotor for use in Kuroshio currents. Renewable Energy 91:189-195.

Tyagi, A., \& Sen, D., 2006. Calculation of transverse hydrodynamic coefficients using computational fluid dynamic approach. Ocean Engineering, 33(5-6), 798-809.

Vanzwieten,J., 2006. Design of a prototype ocean current turbine-Part I: mathematical modeling and dynamics simulation. Ocean Engineering 33.11-12:1485-1521. 
The submerged tidal current system

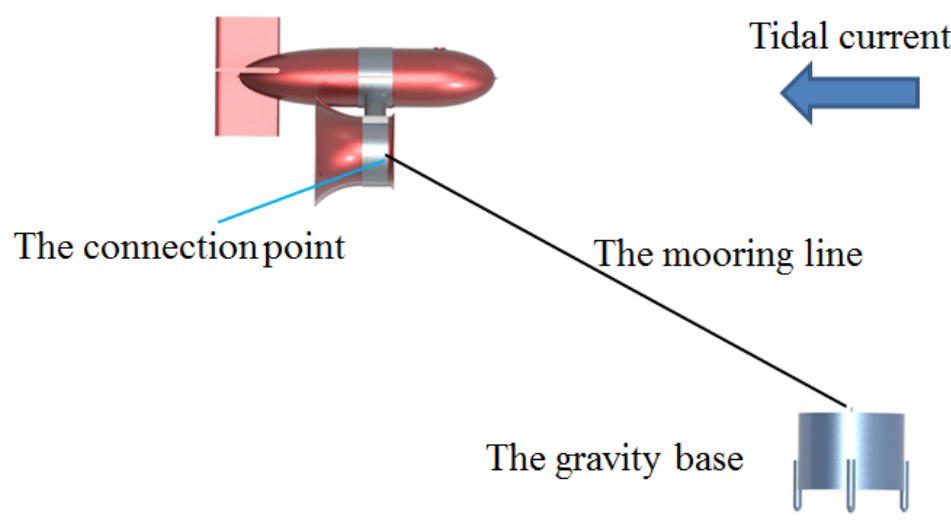

Fig.1 Depiction of the submerged tidal energy device

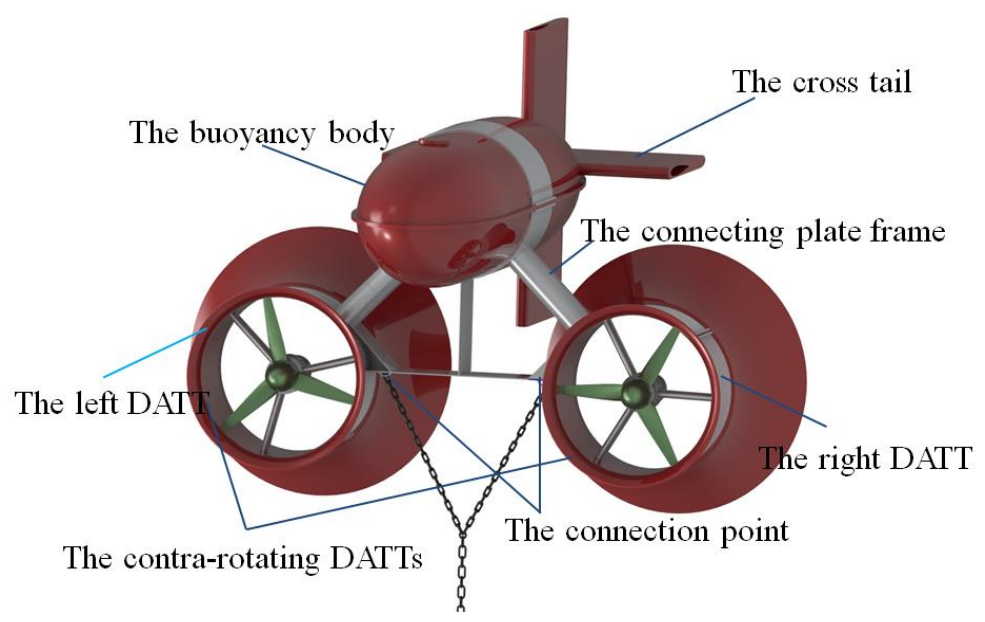

Fig.2 Basic structure of the submerged tidal energy device

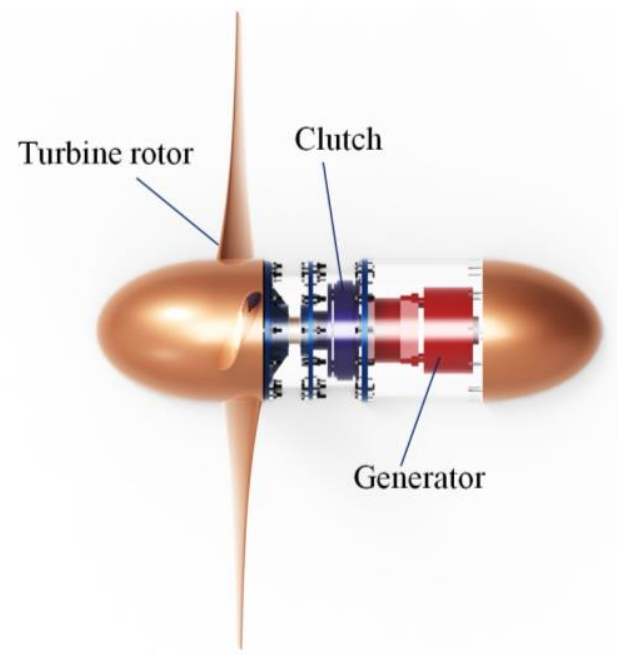

Fig.3 The nacelle structure 
Buoyancy body's hydrodynamic centre

Tidal current
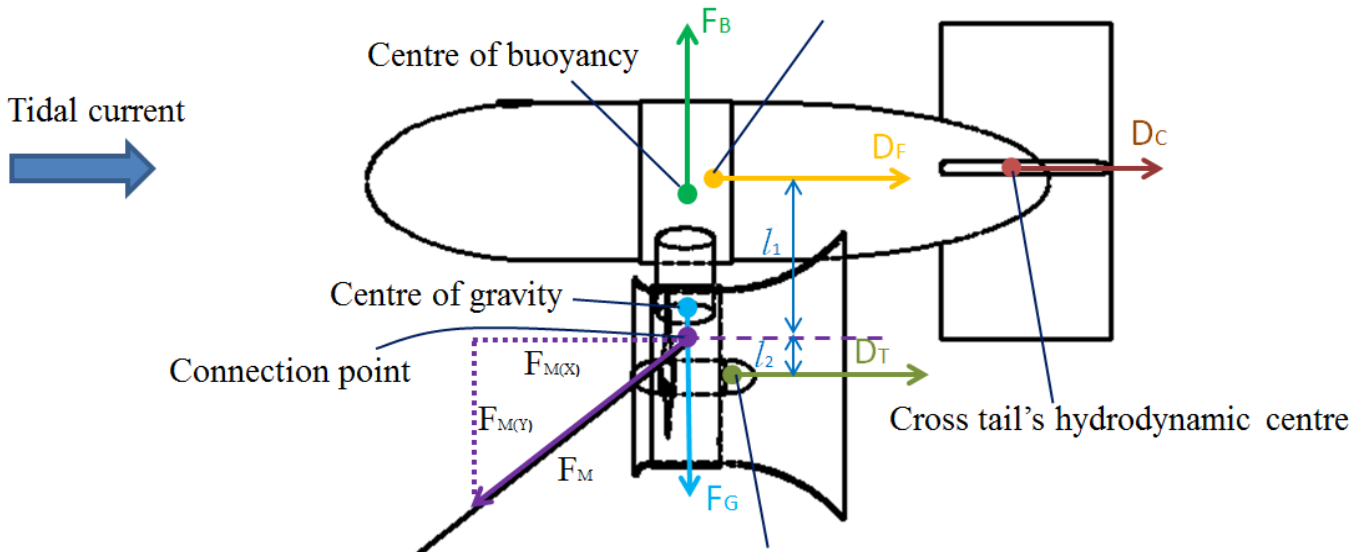

DATT's hydrodynamic centre

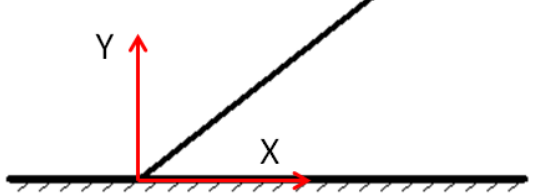

Fig.4 Schematic of device equilibrium analysis at designed tidal current velocity in axial flow

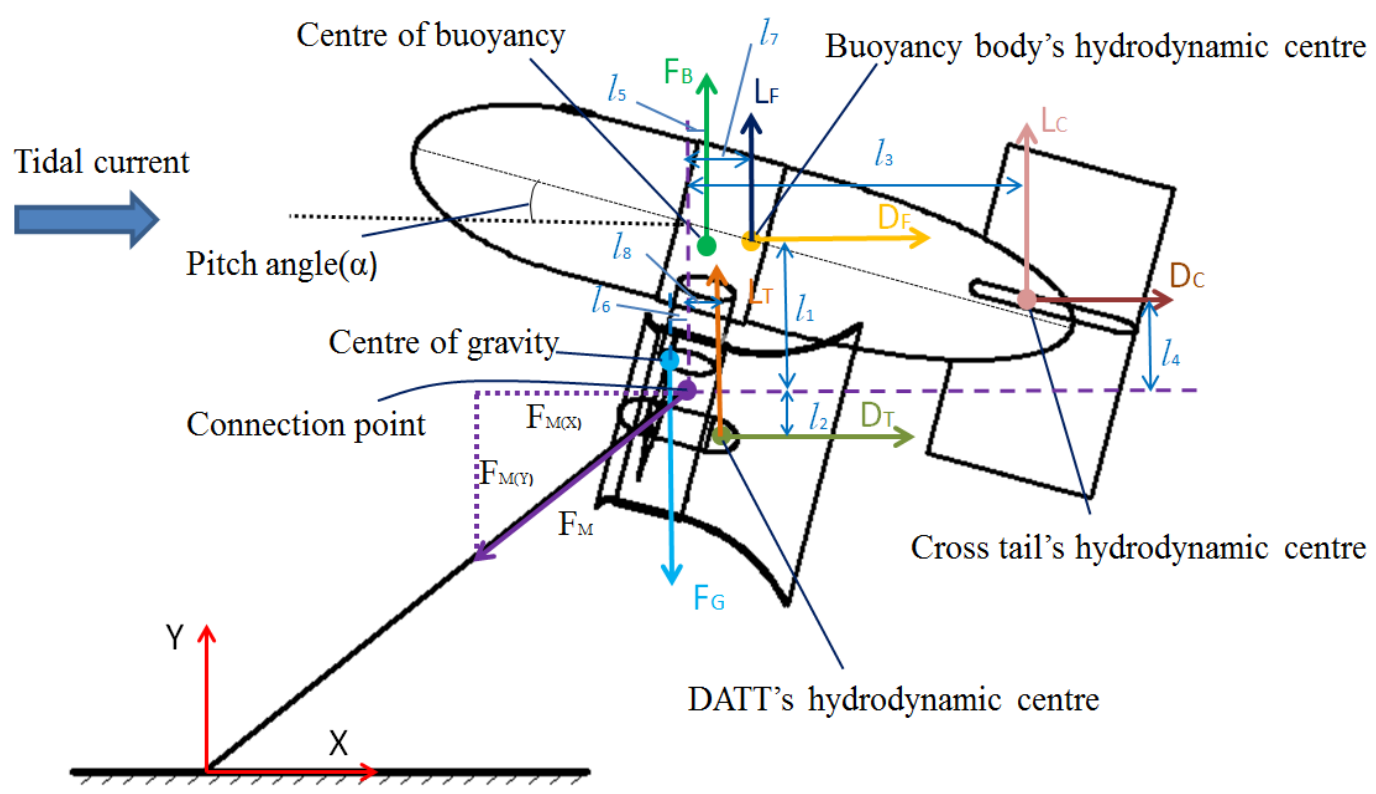

Fig.5 Schematic of device equilibrium analysis at other tidal current velocities in axial flow 


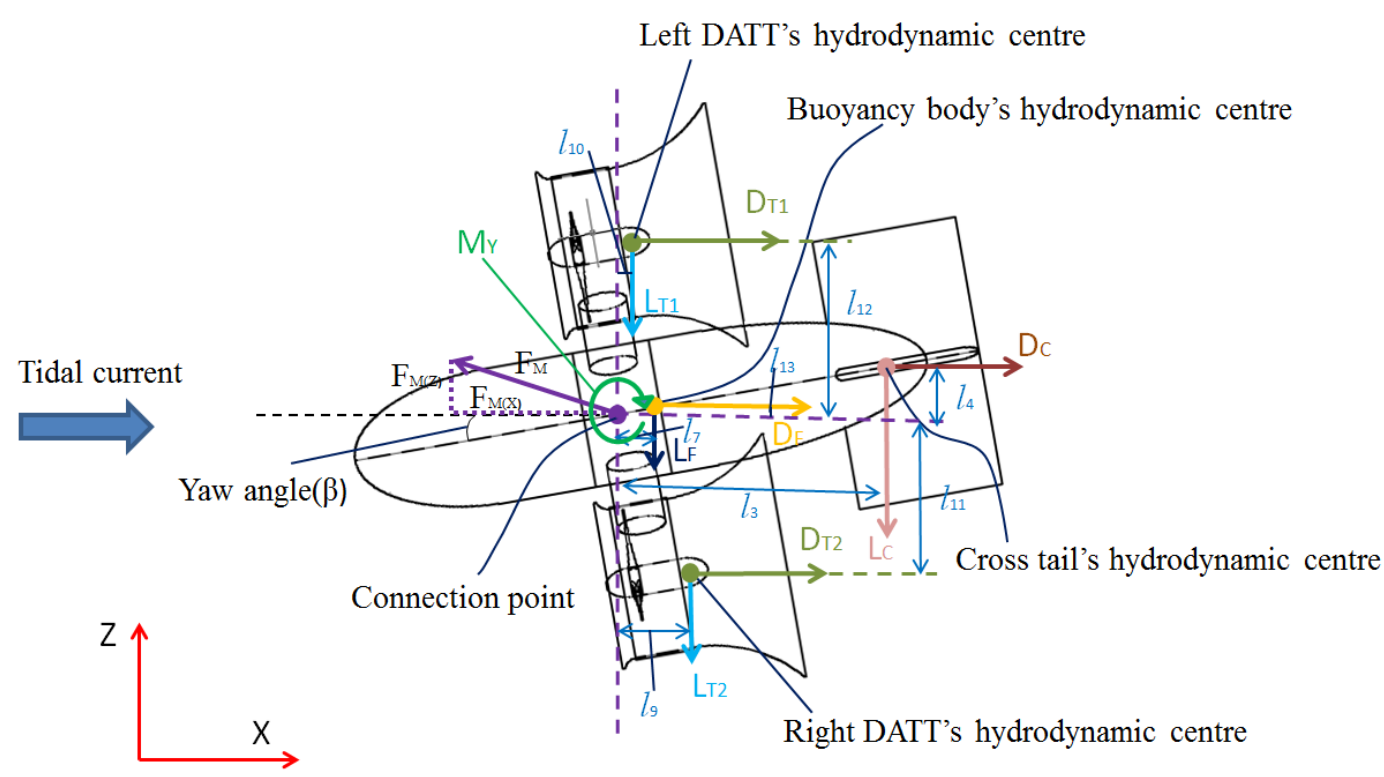

Fig.6 Schematic of device forces and moments analysis in non-axial upstream flow

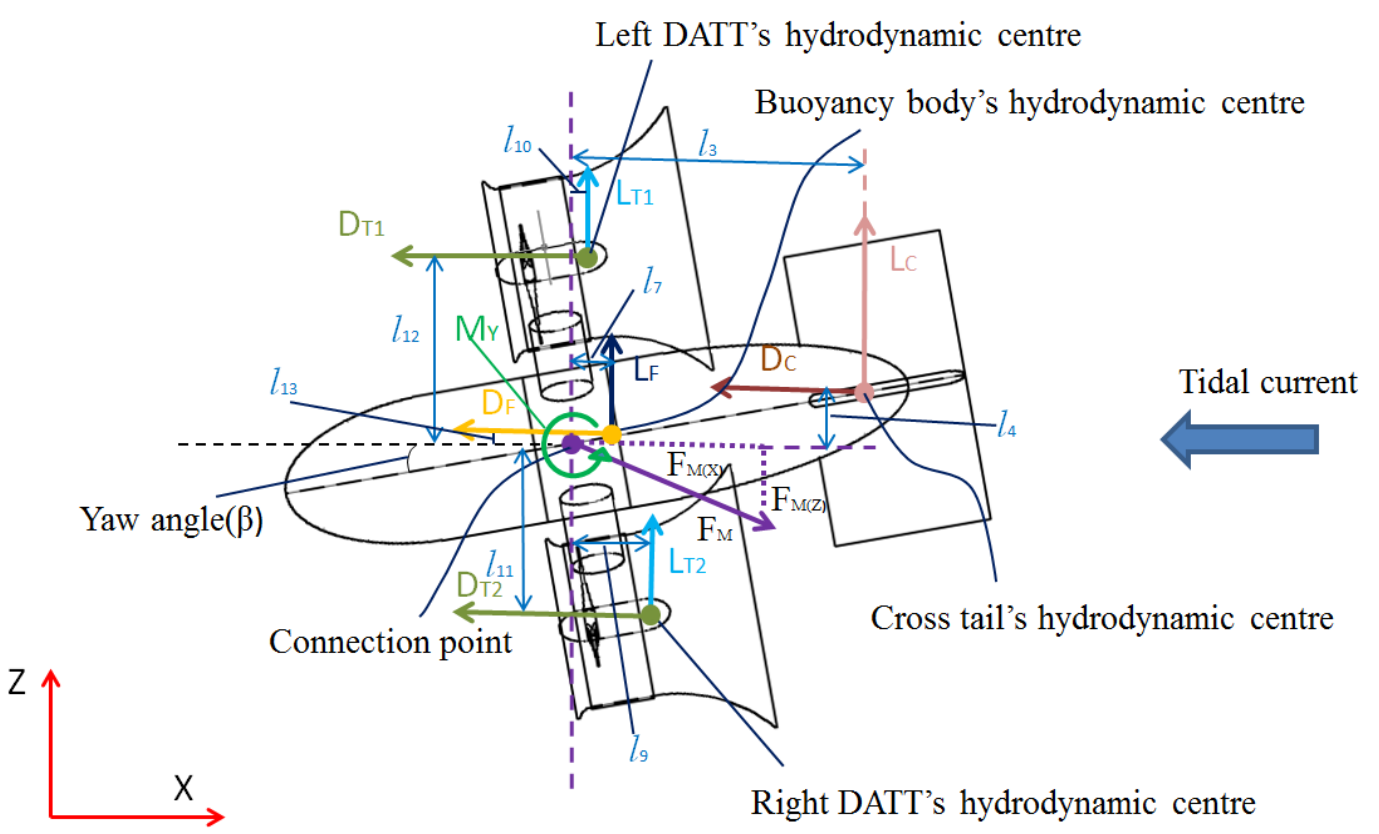

Fig.7 Schematic of device forces and moments analysis in non-axial downstream flow 


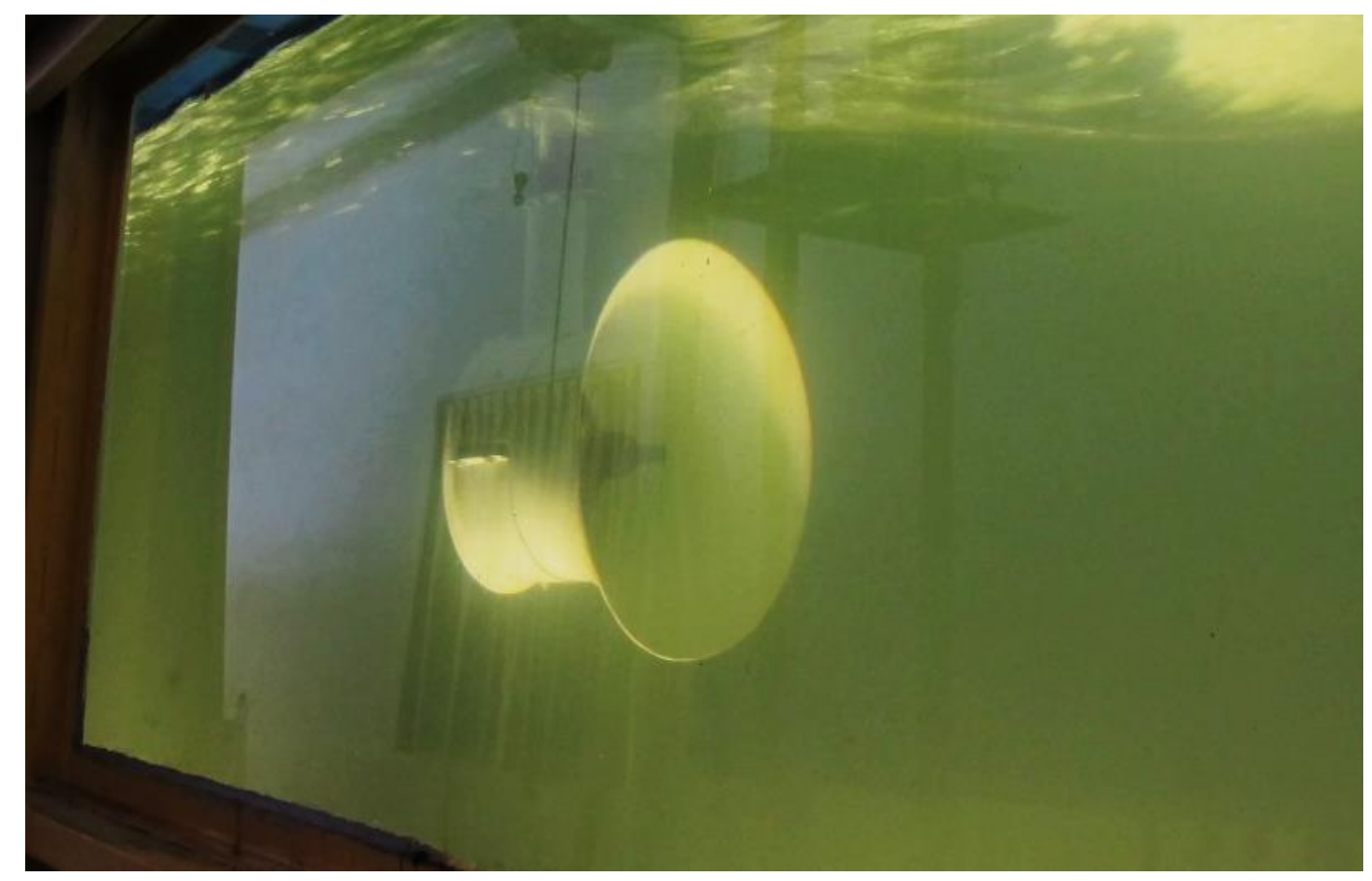

Fig.8 Single DATT model installed in the measuring section of circulating water channel

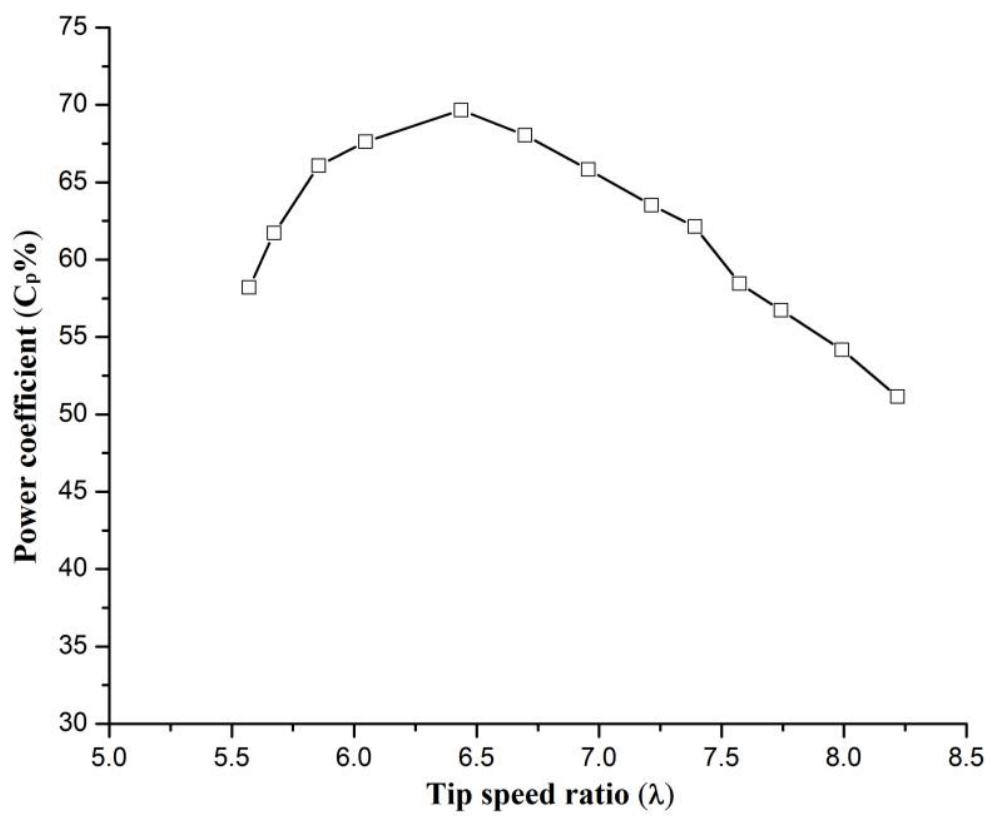

Fig.9 The power coefficients of DATT model 


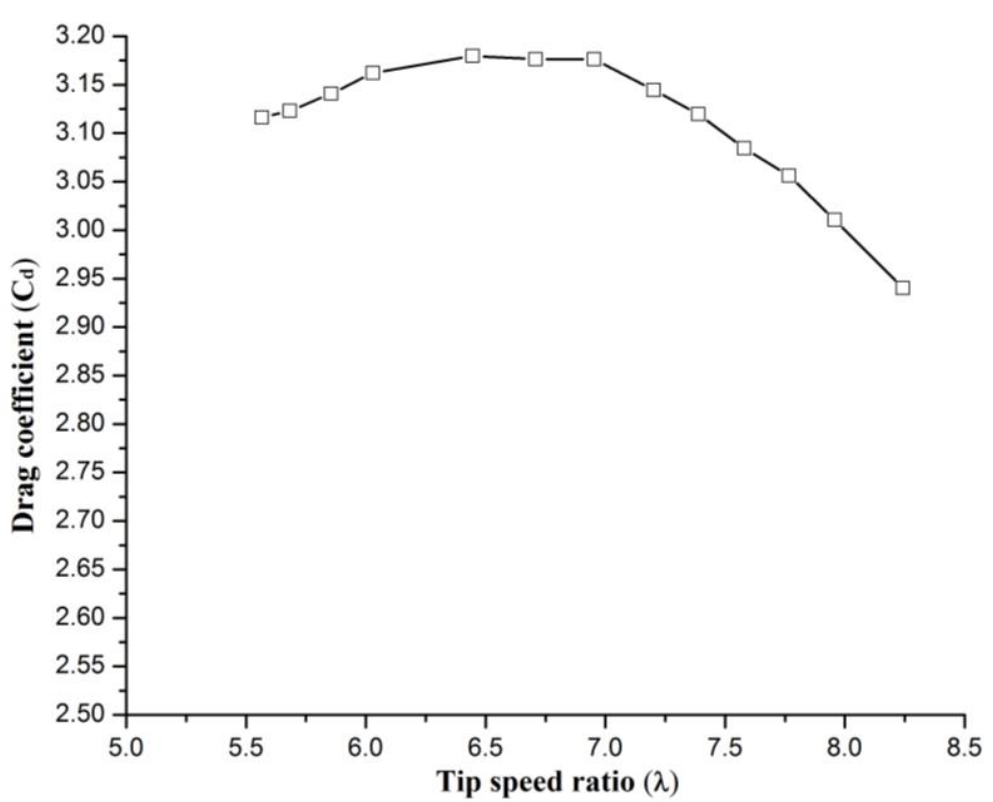

Fig.10 The drag coefficients of DATT model

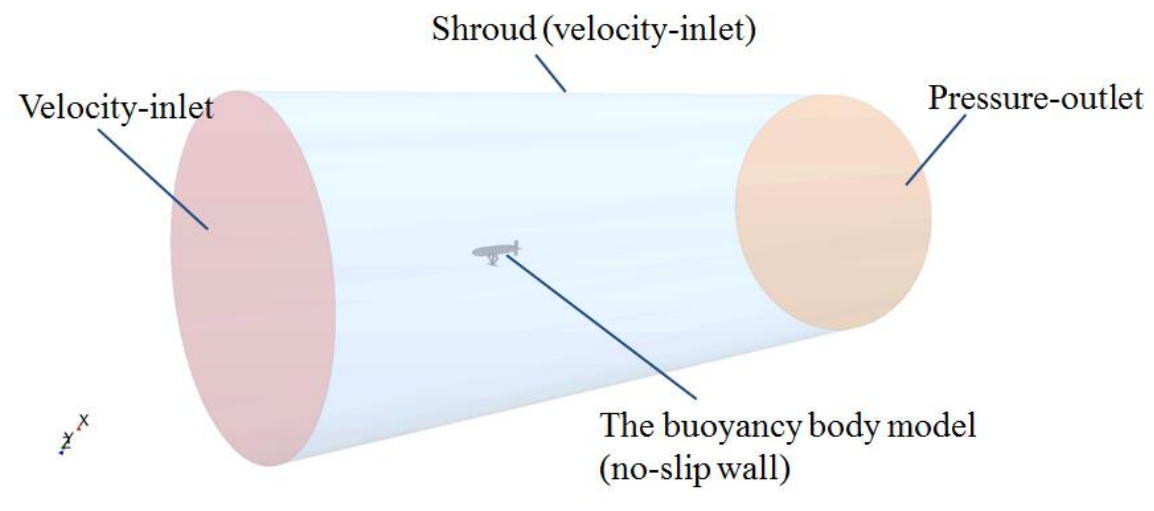

Fig.11 Boundary conditions of the computational domain

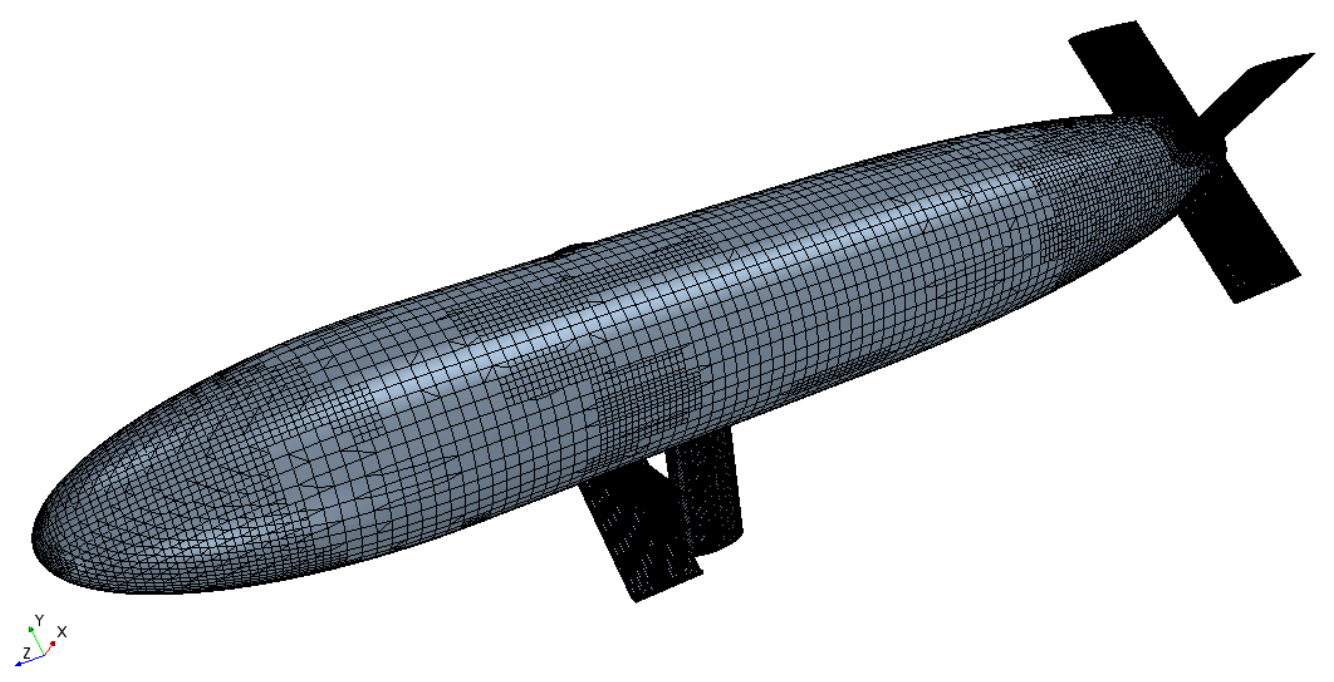

Fig.12 Surface mesh of the 1:5 th scaled buoyancy body model 


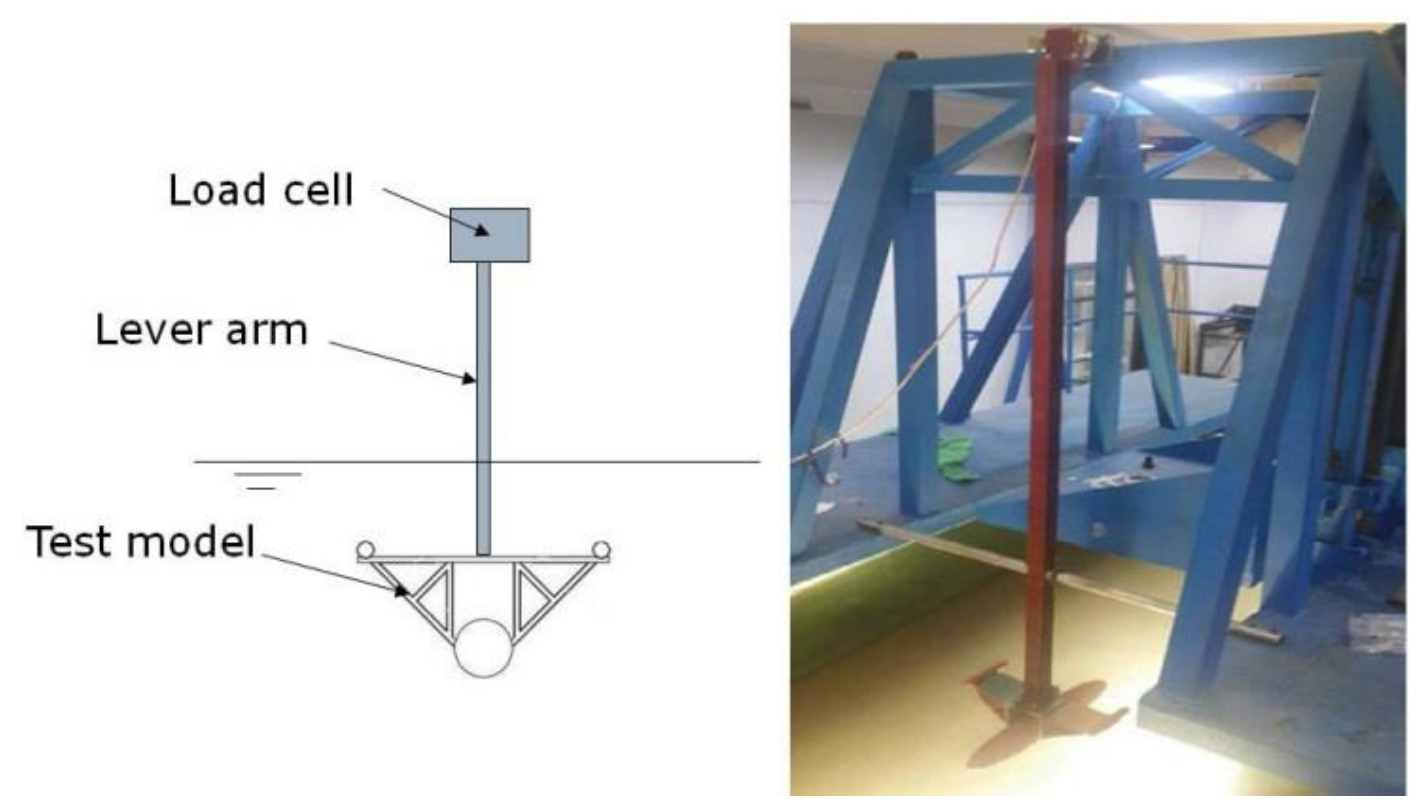

Fig.13 The validation model test set up

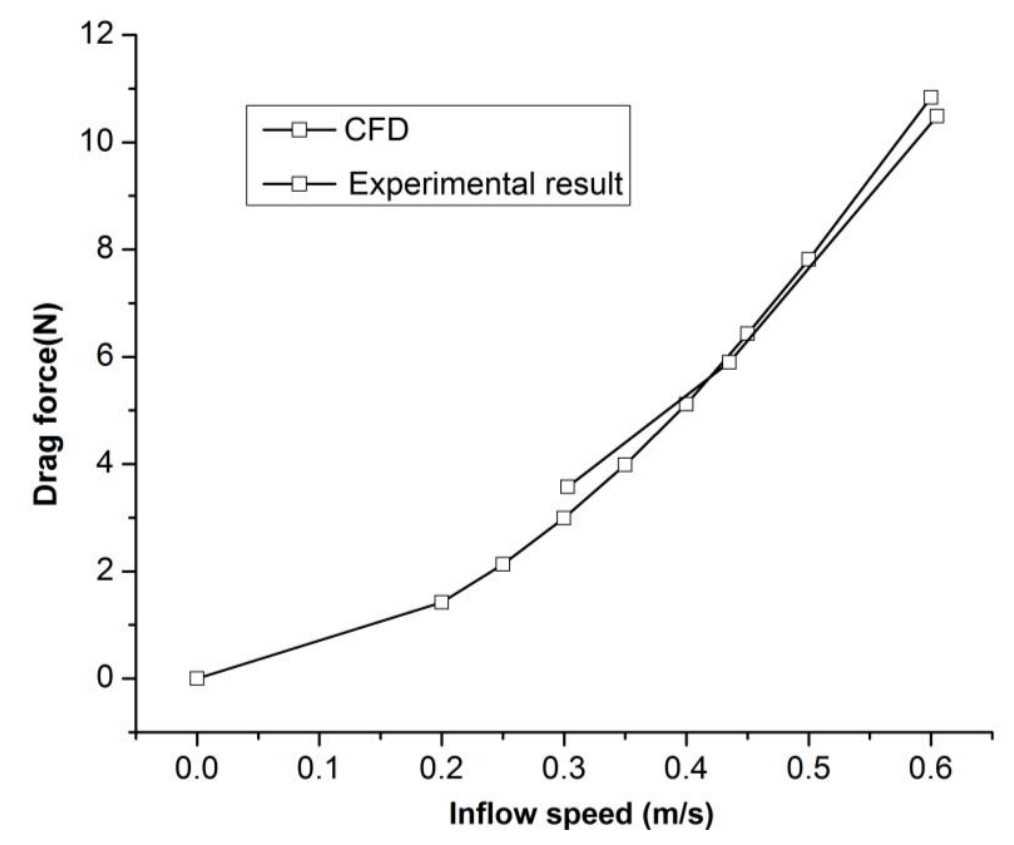

Fig.14 The results of validation model tests and CFD 


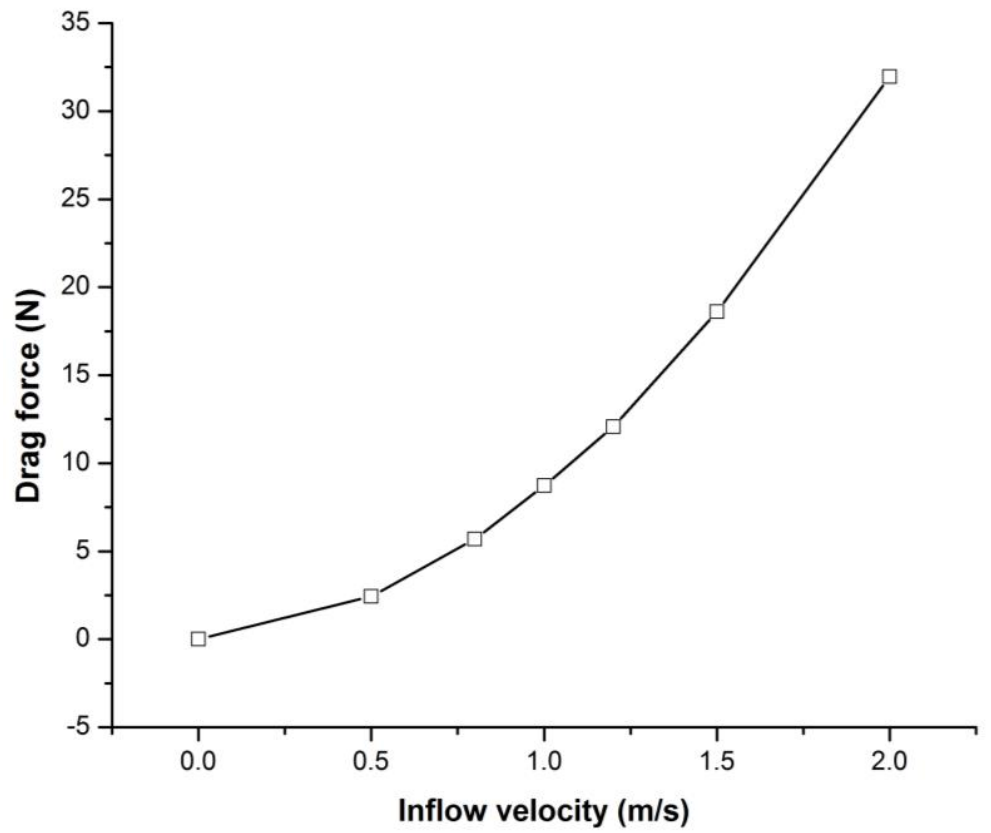

Fig.15 Drag force of the 1:5 th scaled buoyancy body model

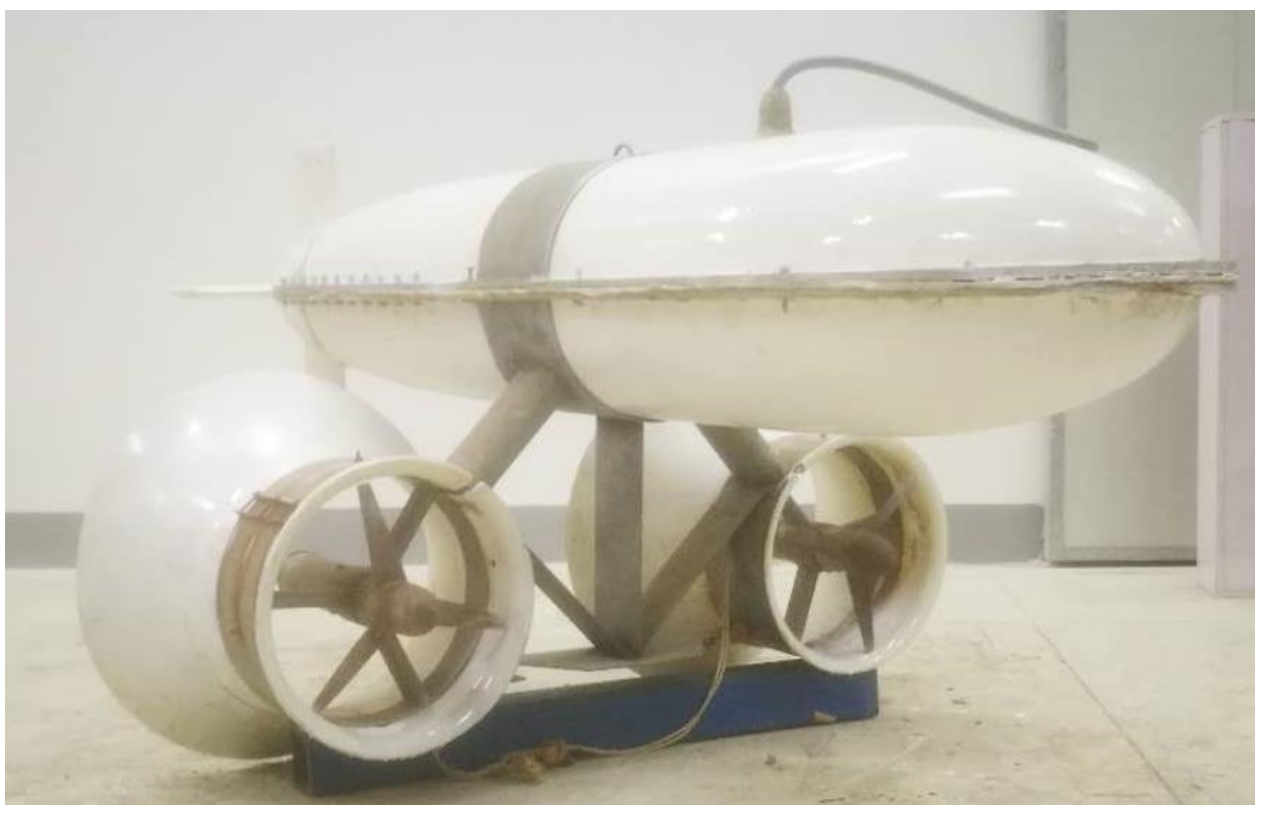

Fig.16 The 1:5 th scaled model
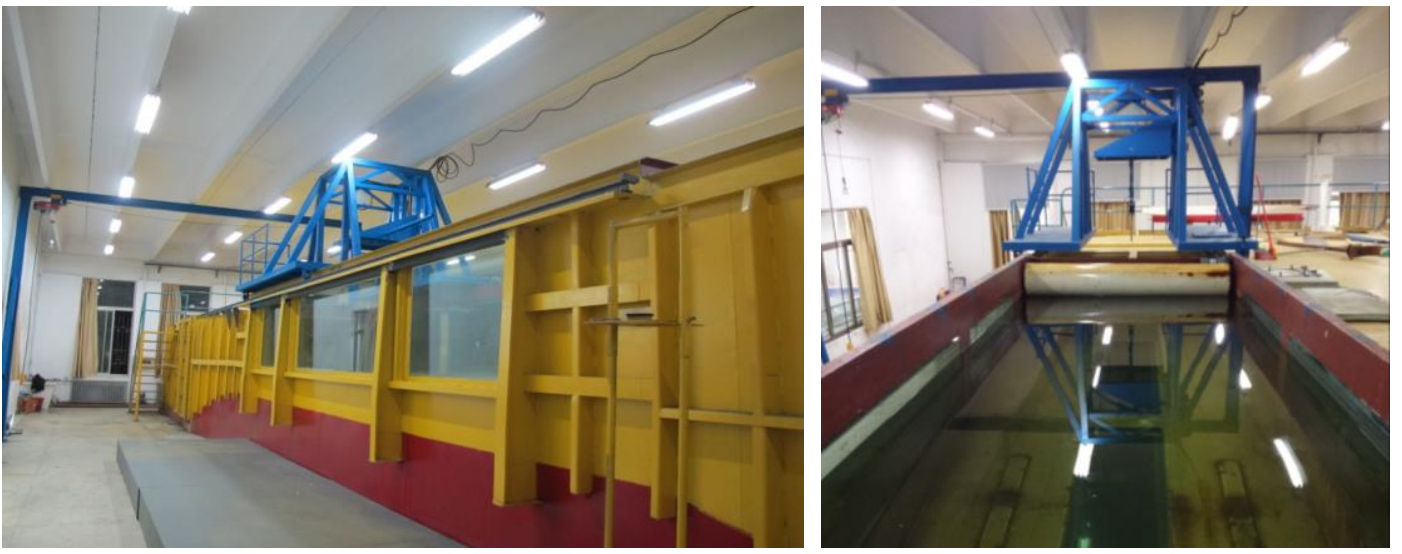

Fig.17 Test section of the circulating water channel 33 / 43 


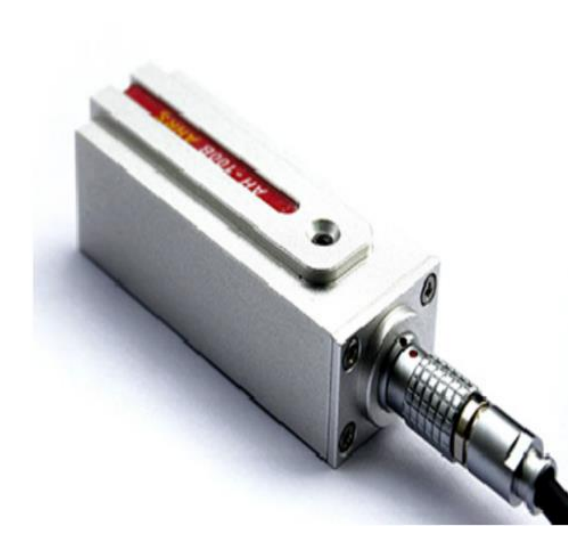

Fig.18 The attitude sensor

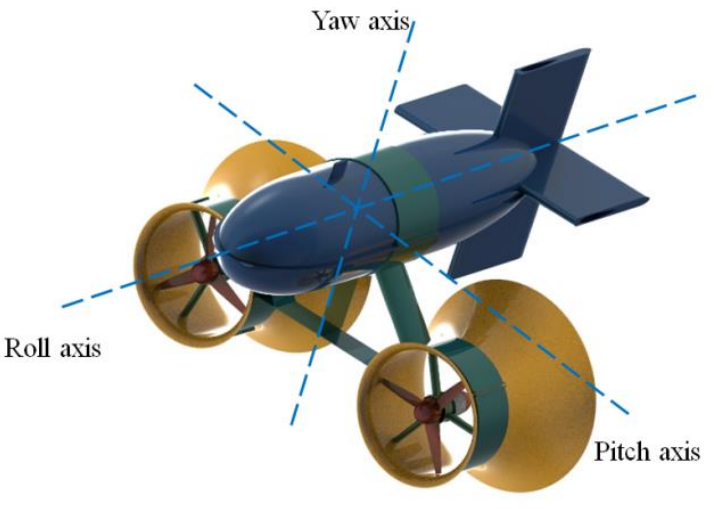

Fig.19 The definition of attitude sensor rotation axis

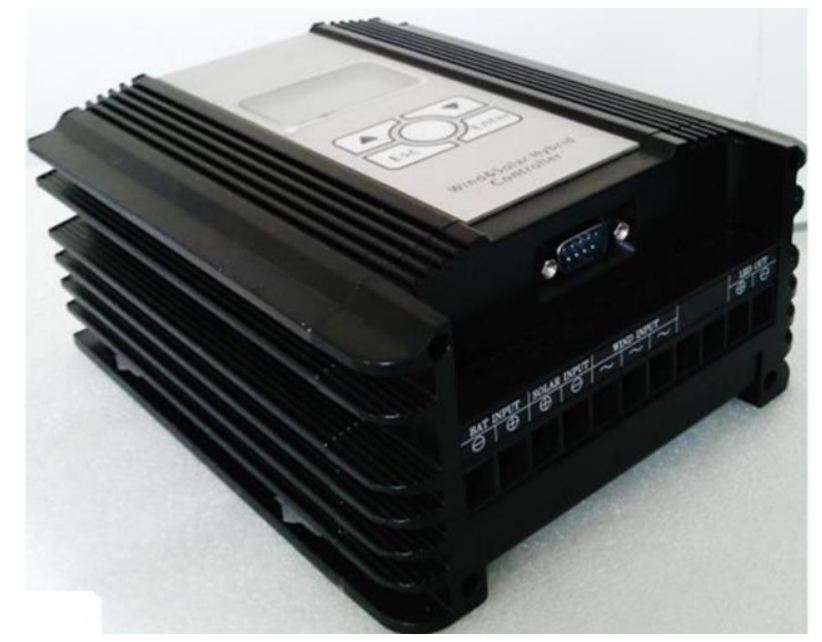

Fig.20 The commercial turbine controller

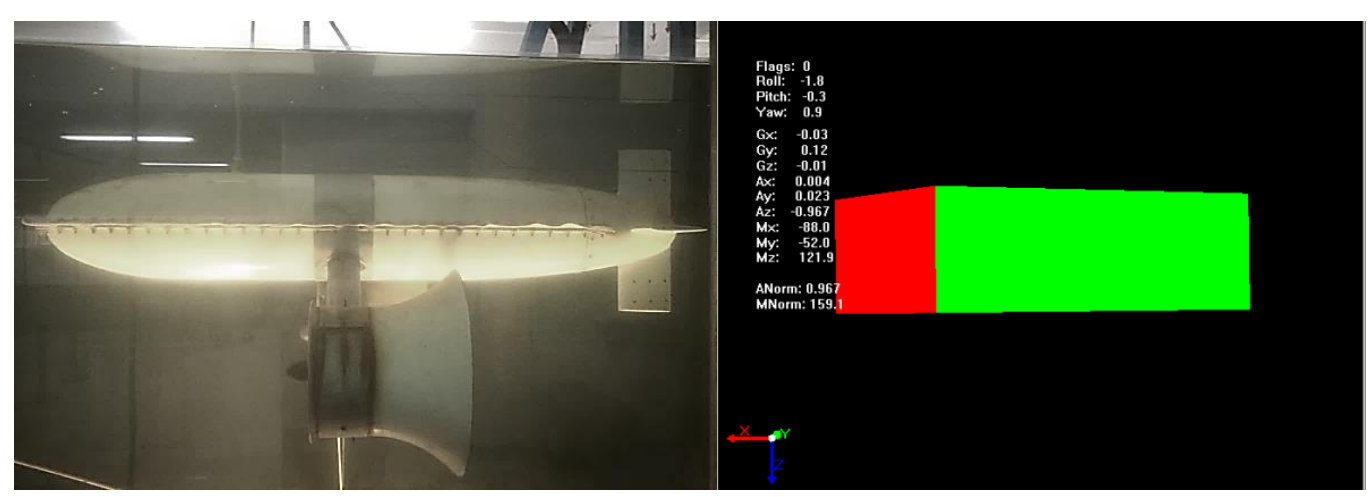

a)

b)

Fig.21 The model in calm water a) and its attitude b) 


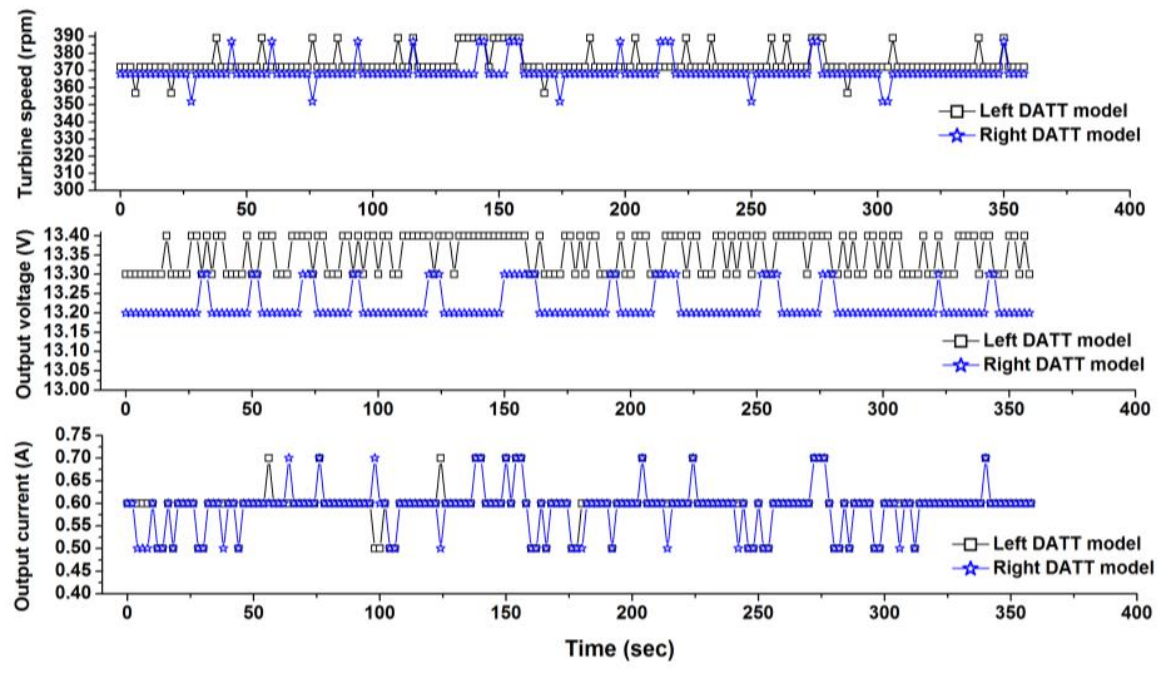

a)
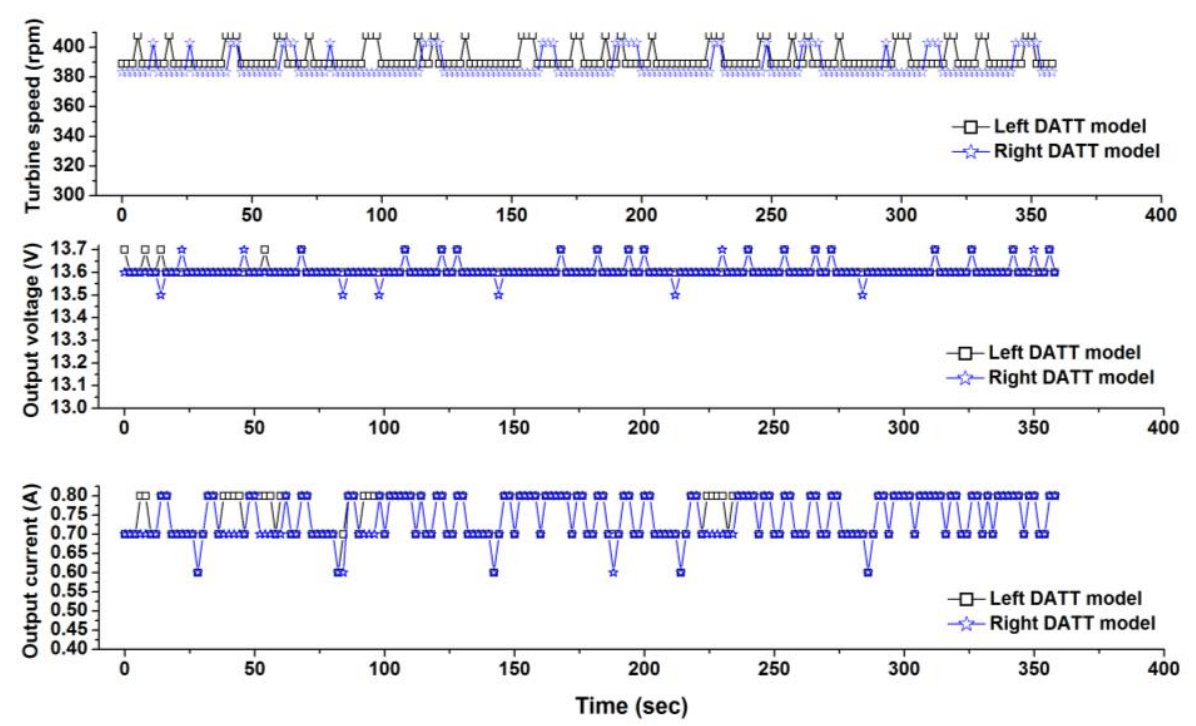

b)
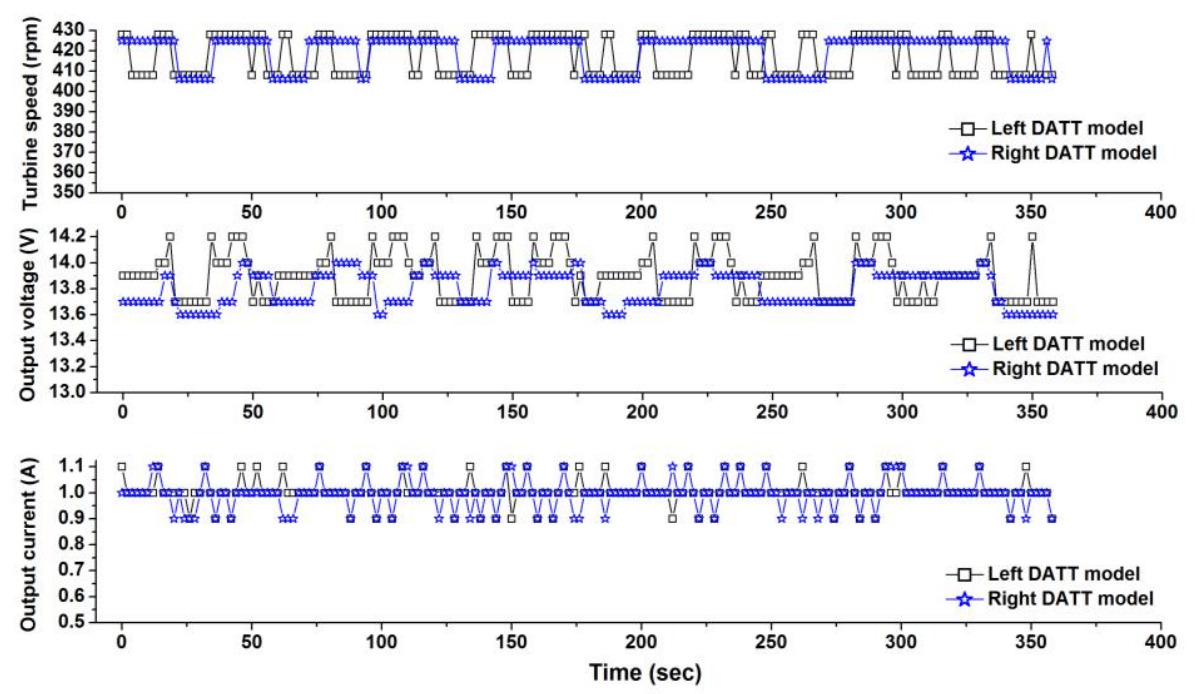
c)

Fig.22 The turbine rotational speed and generator output power at various inflow velocities, a) $0.89 \mathrm{~m} / \mathrm{s}$, b) $0.95 \mathrm{~m} / \mathrm{s}$, c) $1.01 \mathrm{~m} / \mathrm{s}$

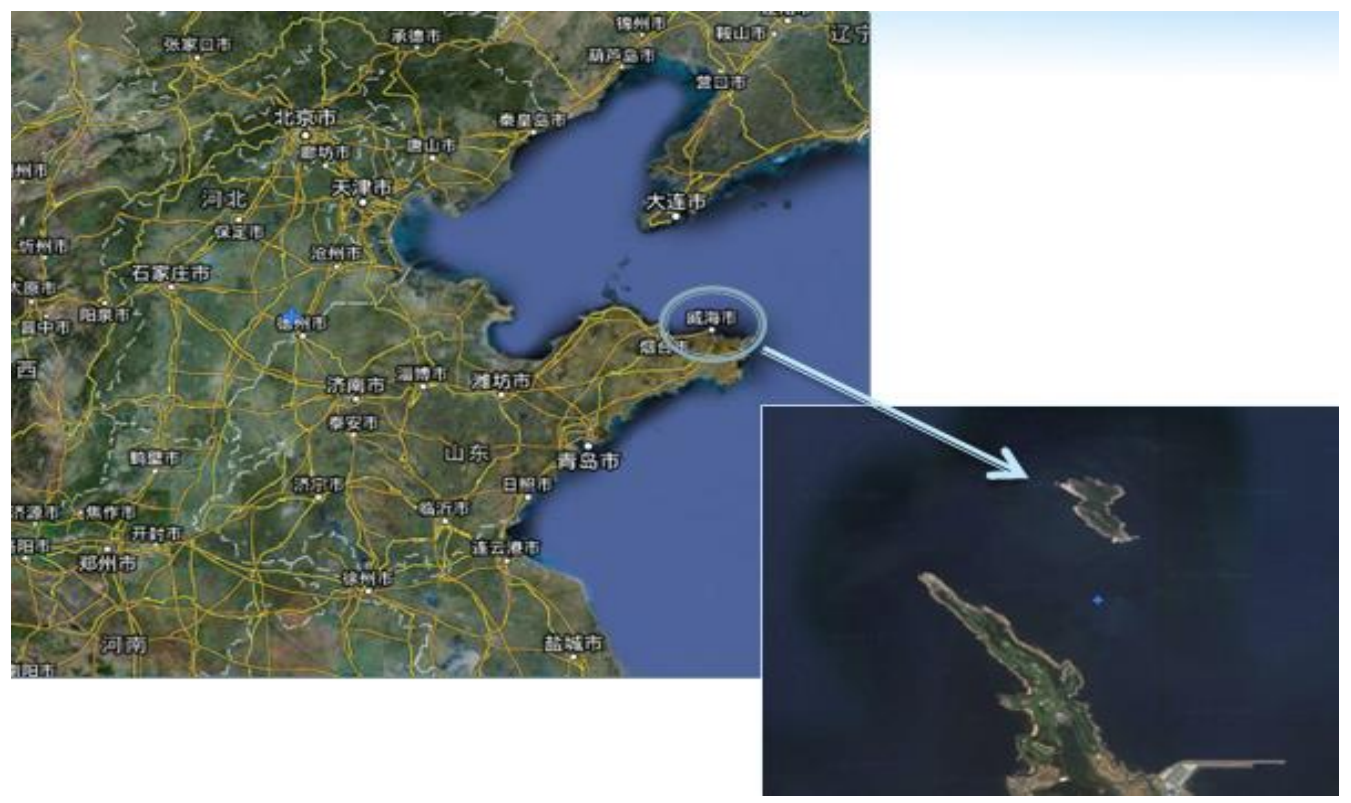

Fig.23 The location of CHU Island

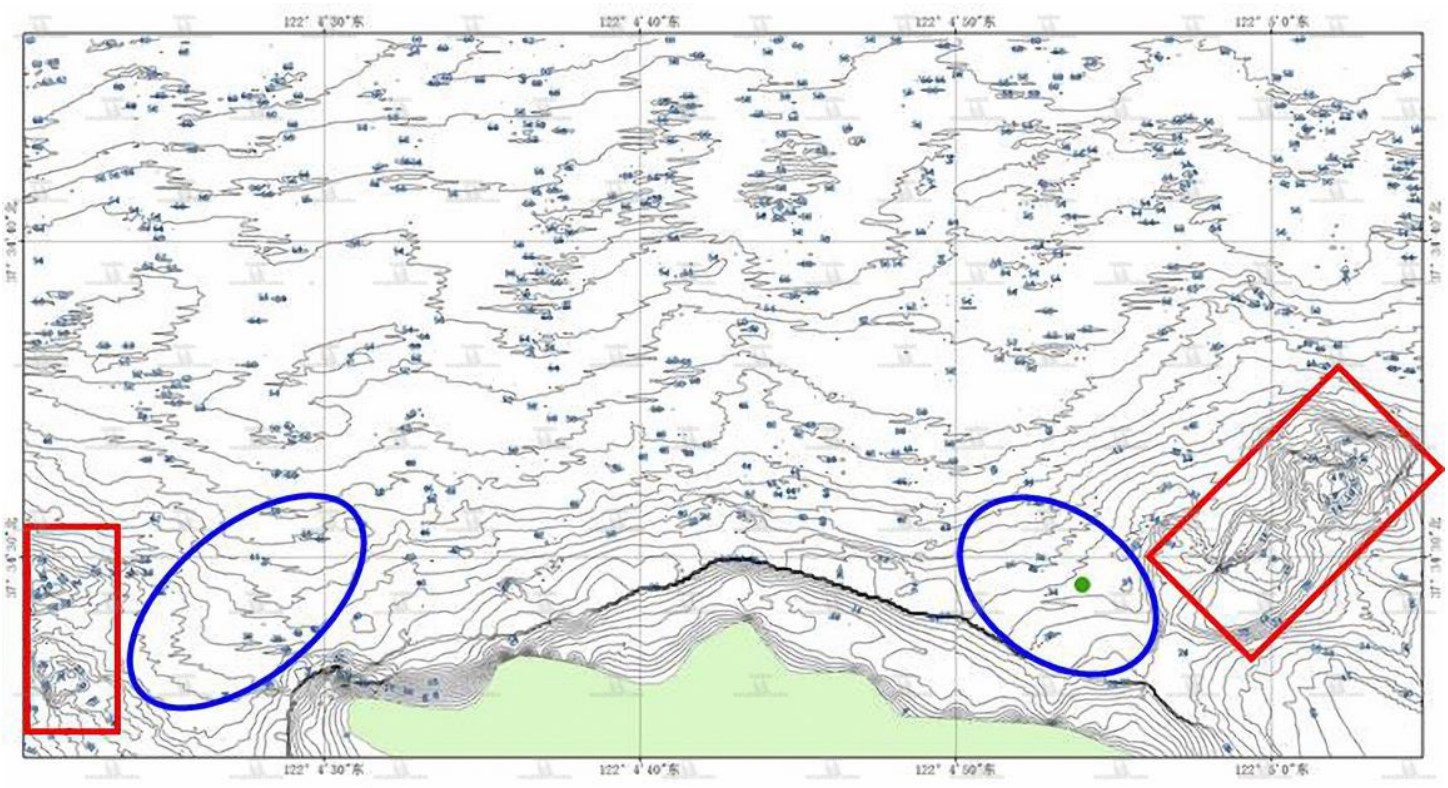

Fig.24 The bathymetric map of the northern CHU Island 


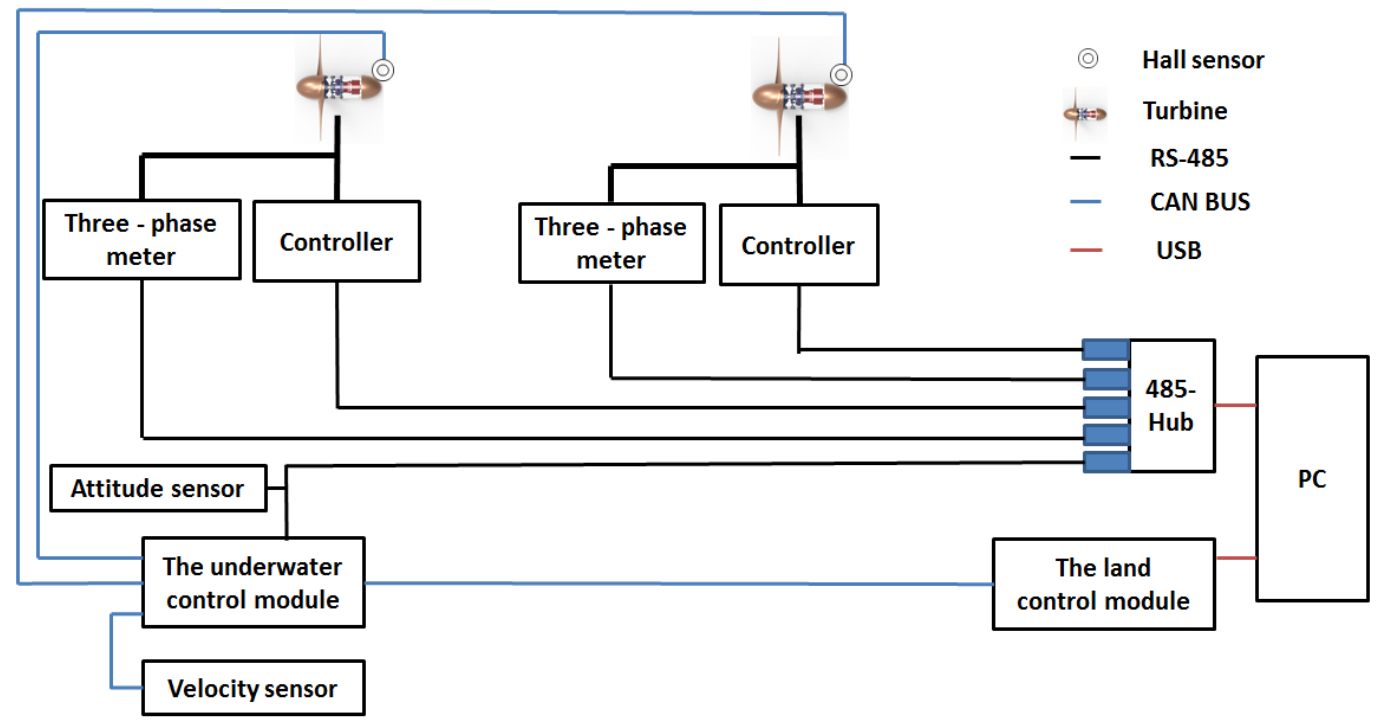

Fig.25 The control system wiring diagram

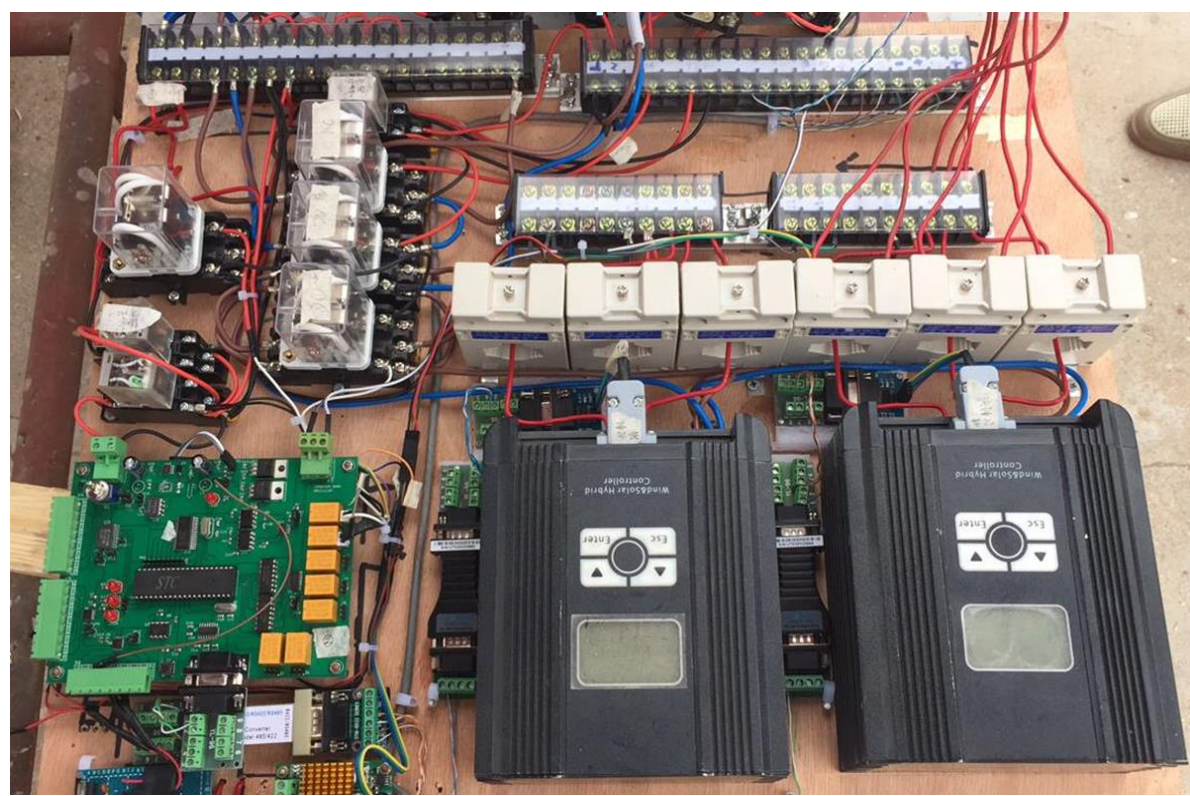

Fig.26 The underwater control subsystem 


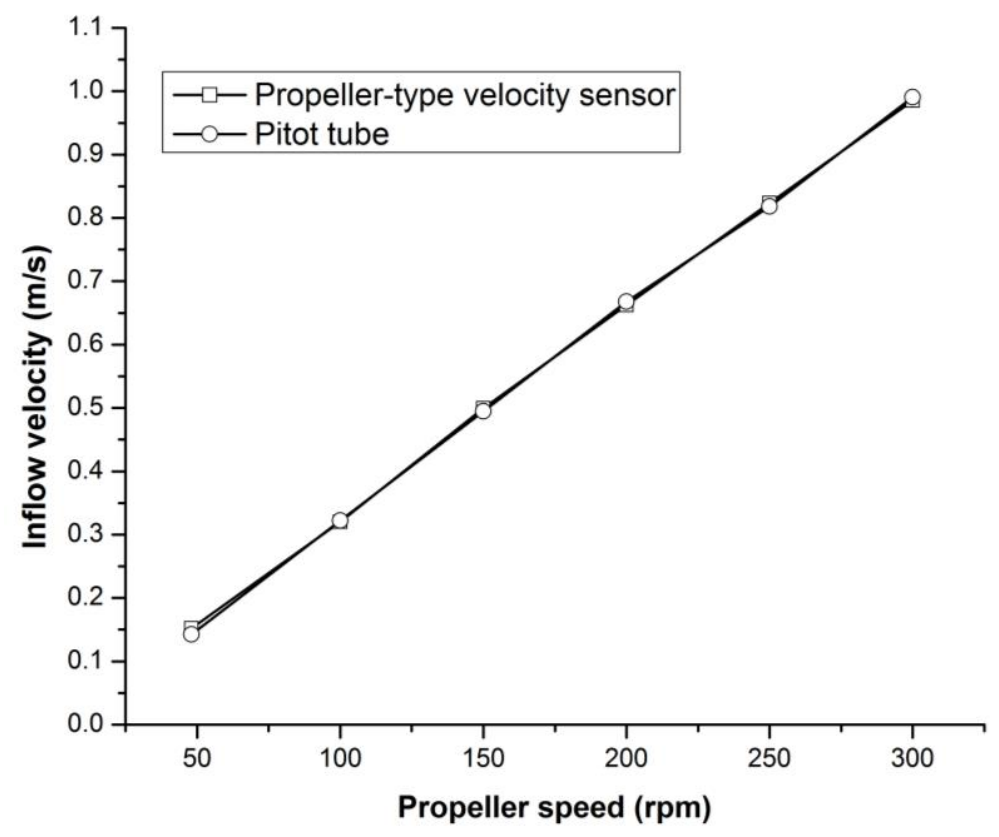

Fig.27 The accuracy test of the propeller-type velocity sensor

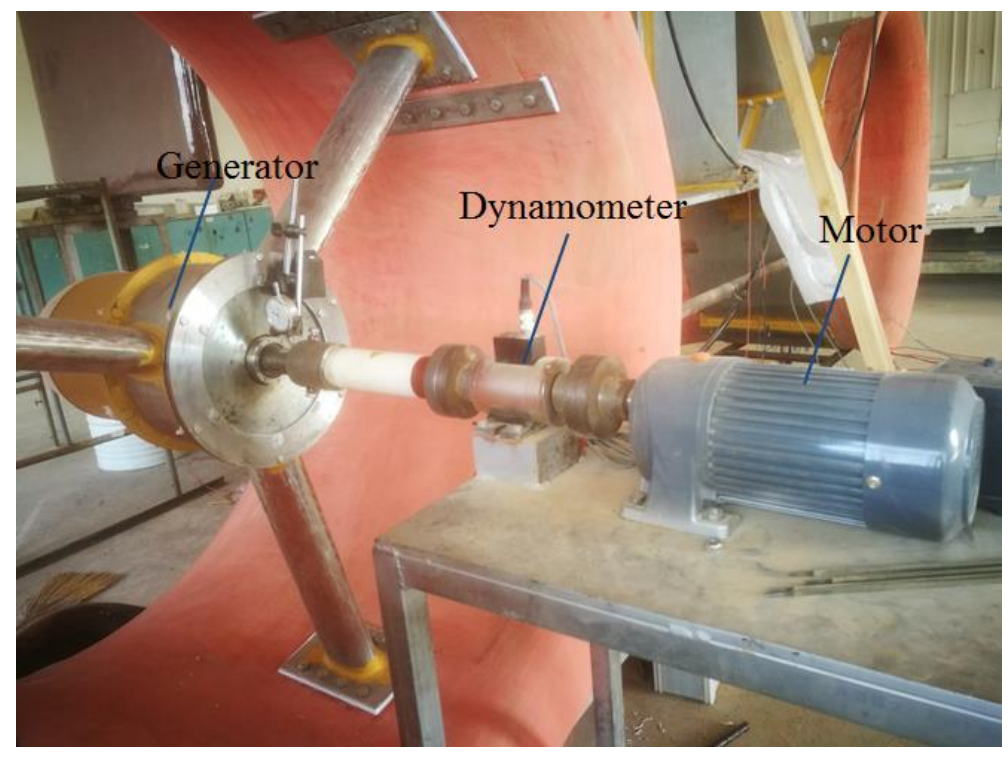

Fig.28 On-shore tests setup for the generator 


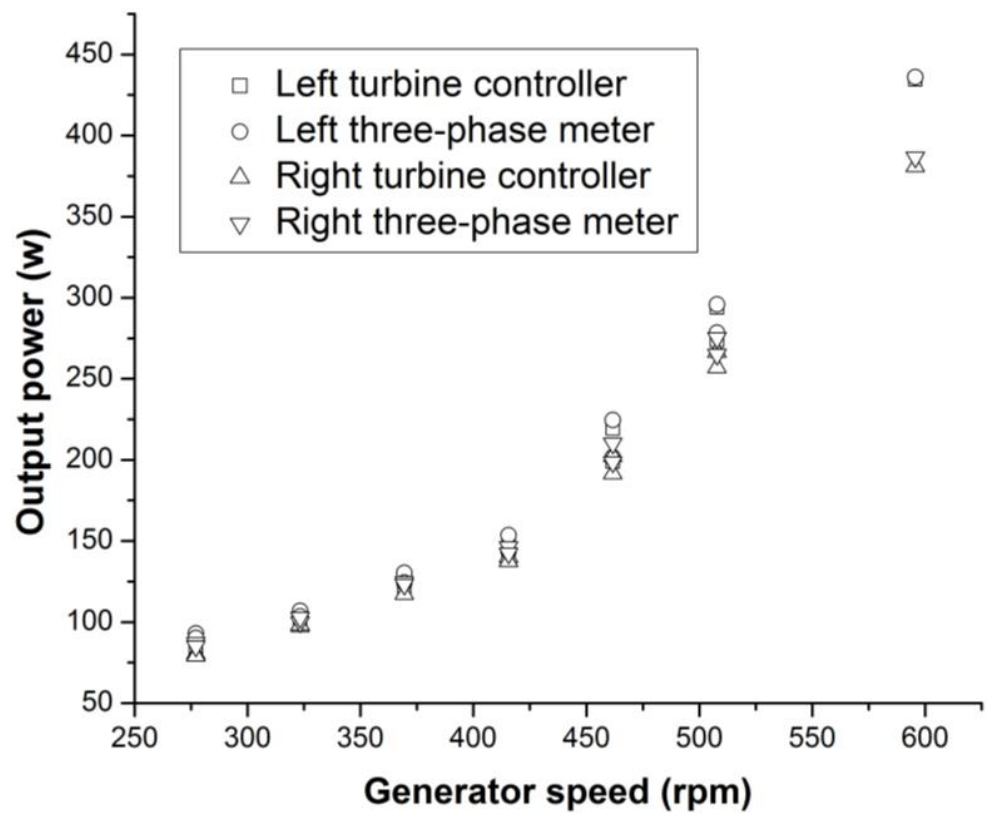

Fig.29 Comparison of output power results between turbine controller and three-phase meter

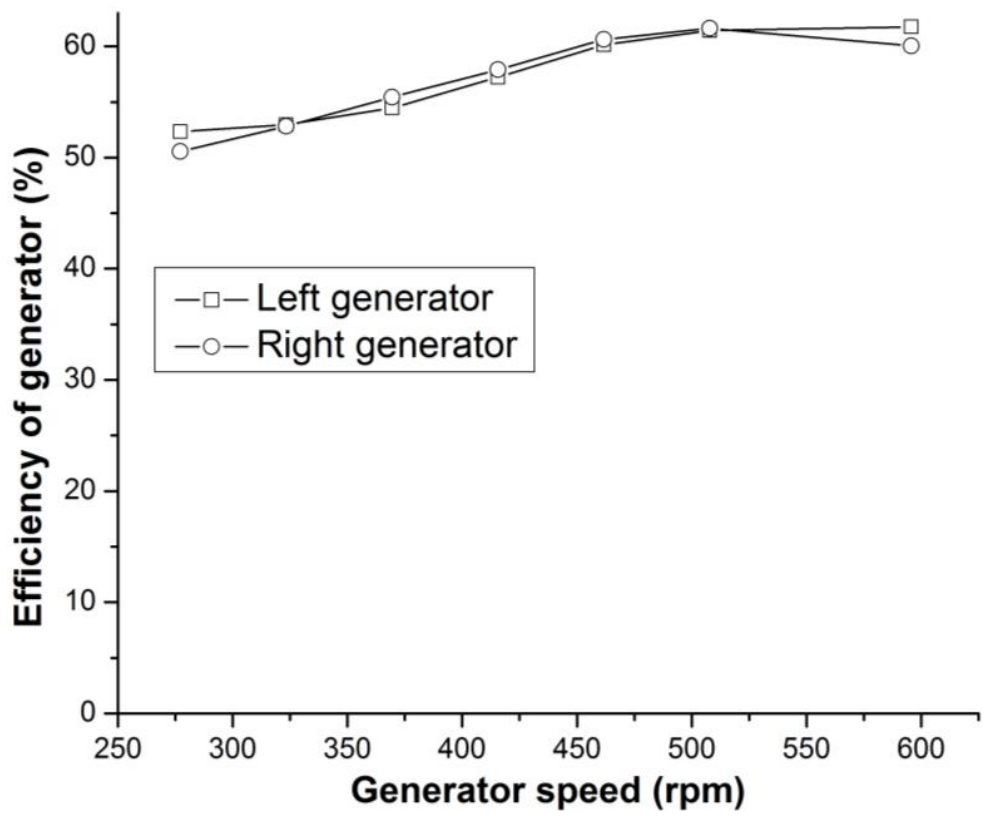

Fig.30 Efficiency of the two generators 


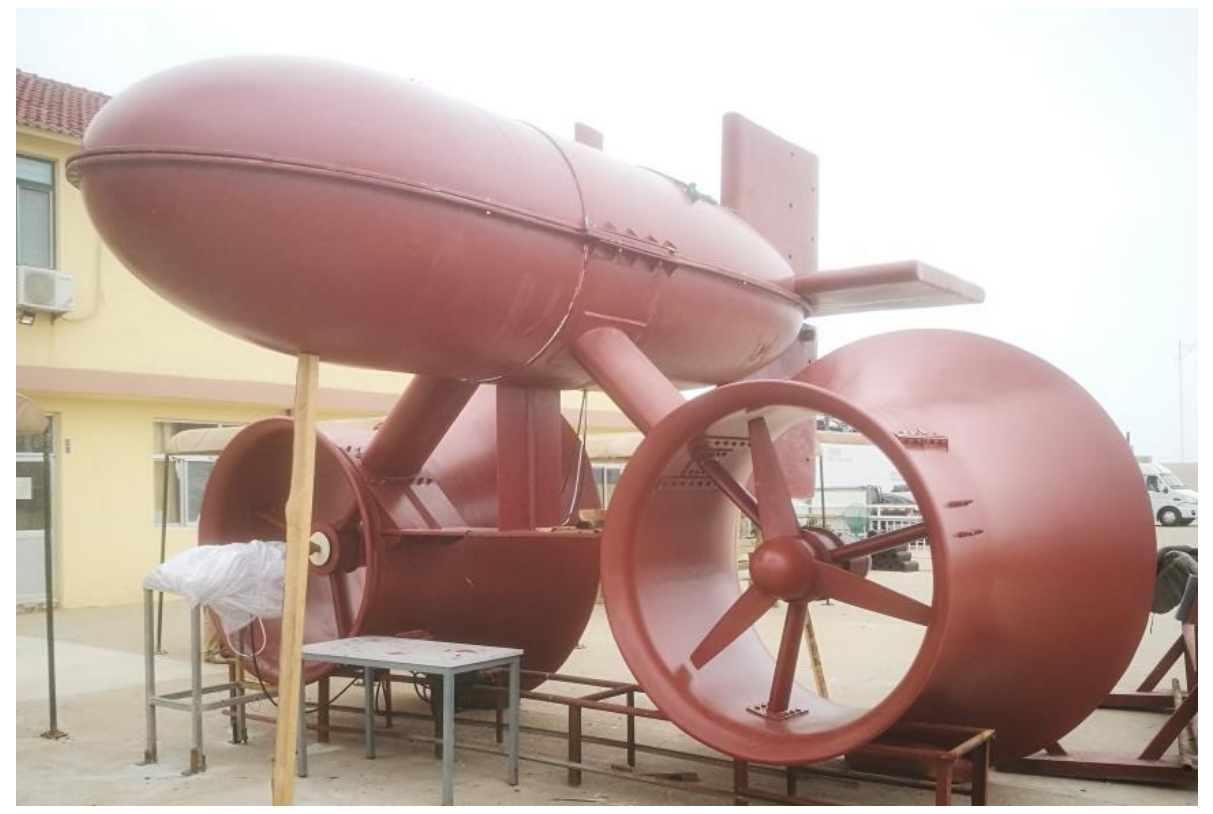

Fig.31 Photograph of the full-scaled submerged tidal current device

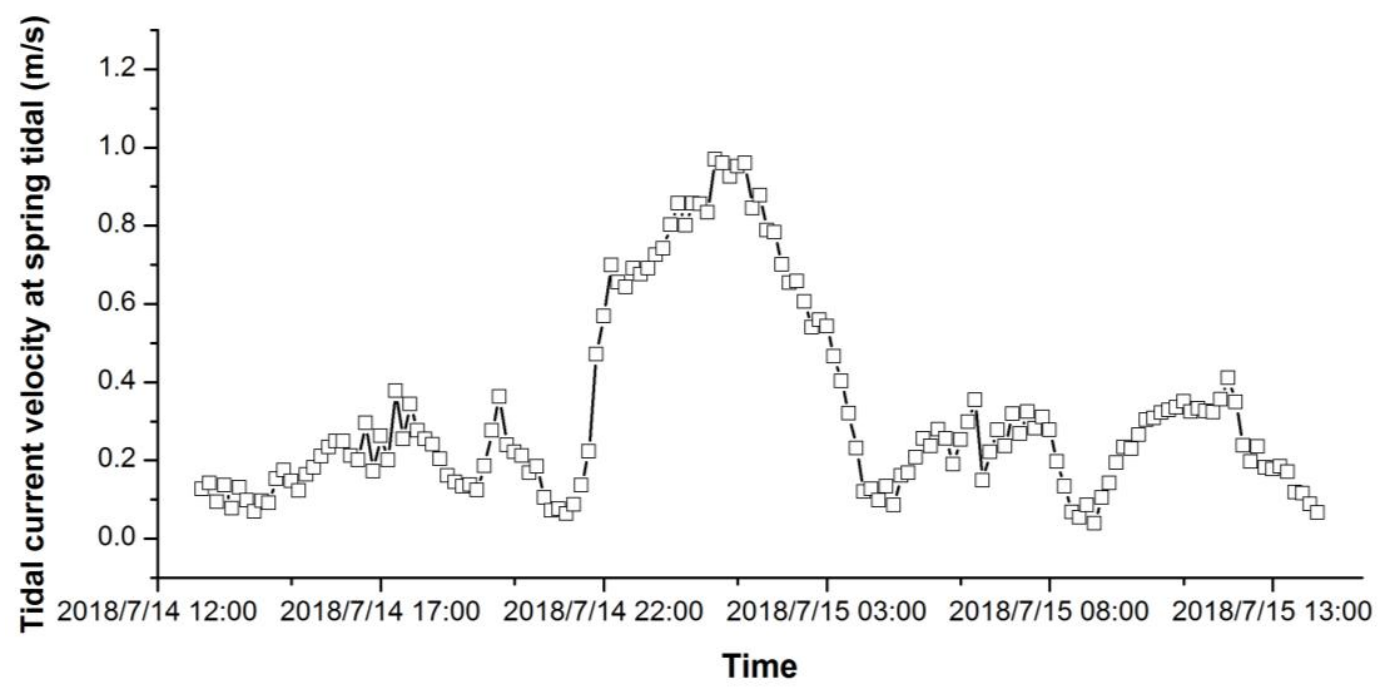

Fig.32 The measured tidal current velocity in July 

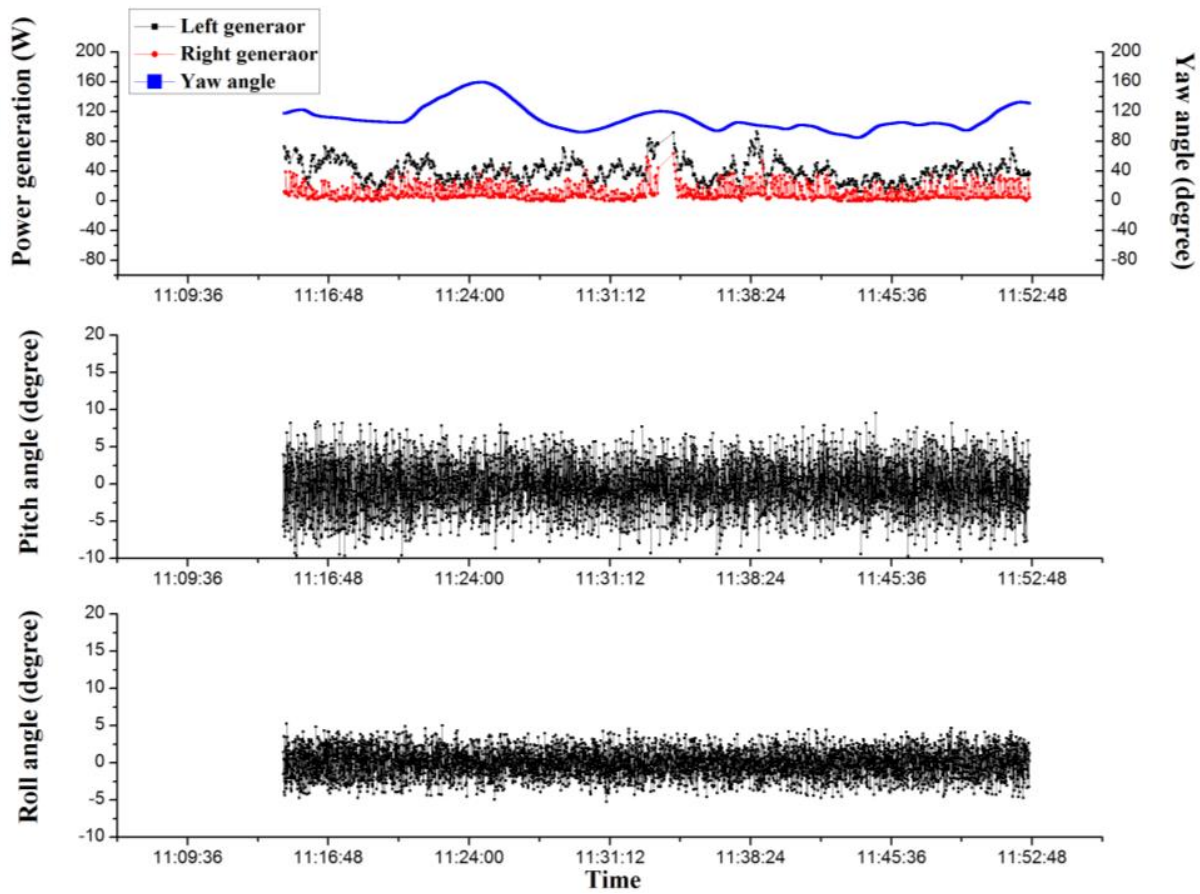

Fig.33 The real- time power generation and attitude of the submerged tidal current device in the second day morning
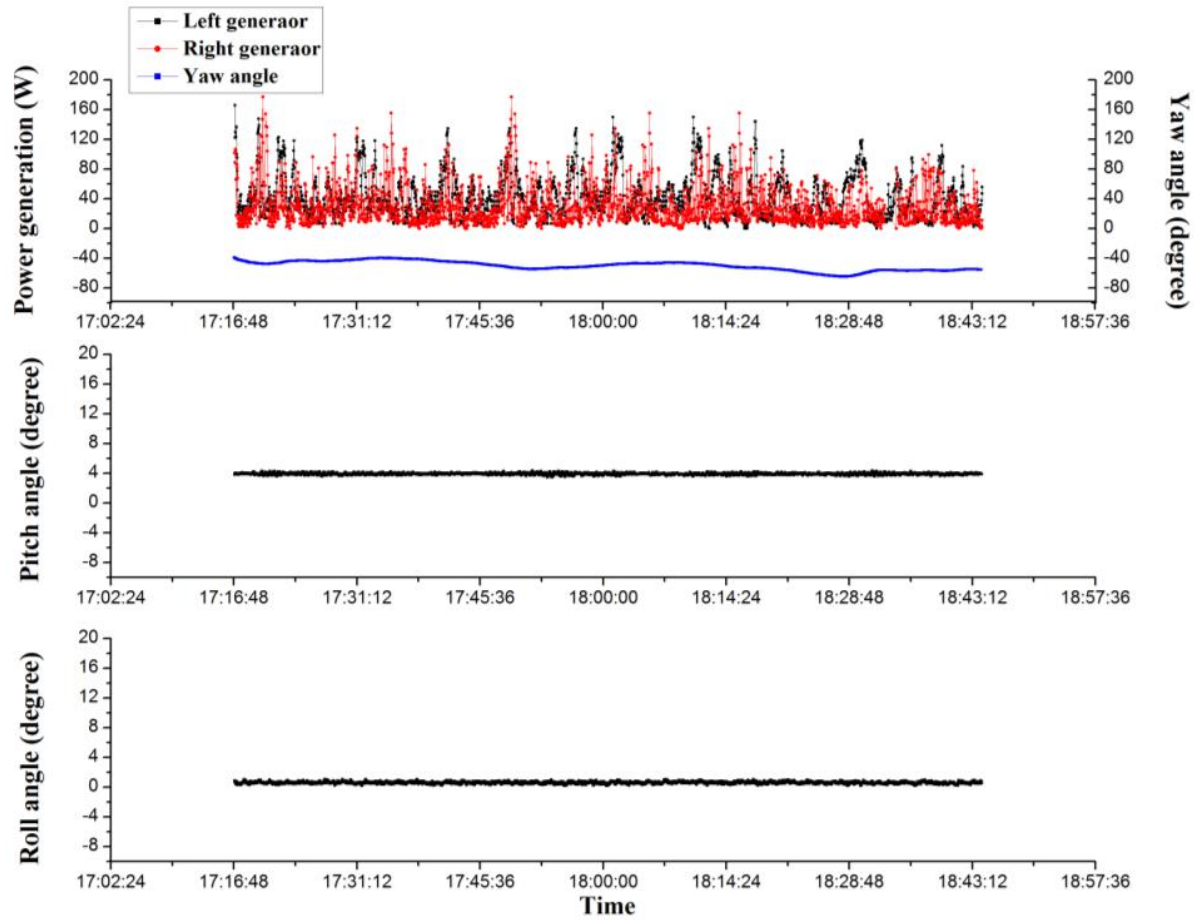

Fig.34 The real- time power generation and attitude of the submerged tidal current device in the third day afternoon 
Table 1 The dimensional parameters of the full-scaled prototype

\begin{tabular}{lll}
\hline & Parameter & Value in $\mathrm{mm}$ \\
\hline 1 & Rotor diameter & 1500.0 \\
2 & The distance between the shafts of two turbines & 3465.0 \\
3 & Diameter of the diffuser at inlet & 1510.0 \\
4 & Diameter of the diffuser at outlet & 2510.0 \\
5 & The length of diffuser & 1850.0 \\
6 & Diameter of the buoyancy body & 1400.0 \\
7 & The total length of buoyancy body & 9185.0 \\
8 & The distance between the centreline of the & 1732.5 \\
\hline
\end{tabular}

Table 2 Mesh independence study

\begin{tabular}{ccccc}
\hline Mesh & Grid quantity & $\mathrm{y}+$ & Inflow velocity (m/s) & Drag force (N) \\
\hline Grid 1 (coarse) & $2.80^{*} 10^{6}$ & 60 & 1 & 8.77684 \\
Grid 2 (medium) & $5.44^{*} 10^{6}$ & 45 & 1 & 8.72757 \\
Grid 3 (Fine) & $1.31^{*} 10^{7}$ & 30 & 1 & 8.82764 \\
\hline
\end{tabular}

Table 3 The test section particulars

\begin{tabular}{cccc}
\hline Length $(\mathrm{m})$ & Breadth $(\mathrm{m})$ & Height $(\mathrm{m})$ & flow velocity range $(\mathrm{m} / \mathrm{s})$ \\
\hline 8 & 2 & 1.3 & $0.2^{\sim} 2$ \\
\hline
\end{tabular}

Table 4 Parameters of the attitude sensor (AH100B)

\begin{tabular}{llll}
\hline Motion & Yaw & Pitch & Roll \\
\hline Measurement range & $\pm 180^{\circ}$ & $\pm 90^{\circ}$ & $\pm 180^{\circ}$ \\
Measurement accuracy & $<2^{\circ}$ & $<1.5^{\circ}$ & $<1.5^{\circ}$ \\
Resolution & $<0.1^{\circ}$ & $<0.1^{\circ}$ & $<0.1^{\circ}$ \\
\hline
\end{tabular}

Table 5 The power output results of 1:5 scaled model tests

\begin{tabular}{|c|c|c|c|c|c|c|c|c|}
\hline & $\begin{array}{l}\text { Inflow } \\
\text { velocity } \\
(\mathrm{m} / \mathrm{s})\end{array}$ & $\begin{array}{c}\text { Turbine } \\
\text { rotational } \\
\text { speed } \\
\text { (rpm) }\end{array}$ & $\begin{array}{l}\text { Output } \\
\text { voltage } \\
\text { (V) }\end{array}$ & $\begin{array}{l}\text { Output } \\
\text { current } \\
\text { (A) }\end{array}$ & $\begin{array}{l}\text { Tip } \\
\text { speed } \\
\text { ratio }\end{array}$ & $\begin{array}{c}\text { Generator } \\
\text { efficiency } \\
(\%)\end{array}$ & $\begin{array}{l}\text { Cp } \\
(\%)\end{array}$ & $\begin{array}{l}\text { Standalone } \\
\text { DATT unit } \\
\text { Cp }(\lambda=6.45)\end{array}$ \\
\hline Left & 0.89 & 375.45 & 13.38 & 0.6 & 6.65 & 55.73 & 57.69 & \multirow{6}{*}{$69.60 \%$} \\
\hline \multirow[t]{2}{*}{ DATT } & 0.95 & 392.68 & 13.61 & 0.75 & 6.52 & 56.83 & 60.06 & \\
\hline & 1.01 & 417.68 & 13.90 & 1.01 & 6.49 & 57.88 & 66.45 & \\
\hline Right & 0.89 & 369.16 & 13.22 & 0.59 & 6.53 & 55.73 & 56.74 & \\
\hline \multirow[t]{2}{*}{ DATT } & 0.95 & 387.00 & 13.61 & 0.75 & 6.42 & 56.83 & 59.29 & \\
\hline & 1.01 & 419.30 & 13.801 & 1.00 & 6.51 & 57.88 & 65.05 & \\
\hline
\end{tabular}


Table 6 The average attitude value of 1:5th scaled model at various inflow velocities

\begin{tabular}{lccc}
\hline inflow velocity $(\mathrm{m} / \mathrm{s})$ & pitch angle $\left({ }^{\circ}\right)$ & roll angle $\left({ }^{\circ}\right)$ & yaw angle $\left({ }^{\circ}\right)$ \\
\hline still water & -0.3 & -1.8 & 0.9 \\
0.89 & -2.9 & 2.2 & 2.5 \\
0.95 & -3.2 & 2.6 & 3.7 \\
1.01 & -3.8 & 3.8 & 5.4 \\
\hline
\end{tabular}

Table 7 Parameters of the velocity sensor

\begin{tabular}{llll}
\hline Measurement range & Working depth & Signal frequency & Relative error \\
\hline $0.05-8 \mathrm{~m} / \mathrm{s}$ & $\leqslant 40 \mathrm{~m}$ & 2 signals $/$ revolution & $\leqslant \pm 5 \%$ \\
\hline
\end{tabular}

Table 8 The average measurement power generation of prototype

\begin{tabular}{ccccc}
\hline Time & $\begin{array}{c}\text { Right generator } \\
(\mathrm{W})\end{array}$ & $\begin{array}{c}\text { Right generator } \\
\text { rotational } \\
\text { speed (RPM) }\end{array}$ & $\begin{array}{c}\text { Left generator } \\
\text { (W) }\end{array}$ & $\begin{array}{c}\text { Left generator } \\
\text { rotational } \\
\text { speed (RPM) }\end{array}$ \\
\hline First day morning & 10.85 & 186 & 38.65 & 281 \\
First day night & 32 & 262 & 70.61 & 366 \\
Second day morning & 11.25 & 189 & 39.47 & 293 \\
Second day afternoon & 18.56 & 210 & 40.31 & 290 \\
Third day morning & 15.05 & 203 & 32.52 & 276 \\
Third day afternoon & 28.98 & 244 & 41.87 & 313 \\
\hline
\end{tabular}

Table 9 The average attitude of the full-scaled device

\begin{tabular}{cccc}
\hline Time & Yaw angle $\left({ }^{\circ}\right)$ & Pitch angle $\left({ }^{\circ}\right)$ & Roll angle $\left({ }^{\circ}\right)$ \\
\hline First day morning & 138.86 & 2.77 & 0.46 \\
First day night & -59.24 & 3.37 & 0.30 \\
Second day morning & 112.97 & -0.50 & -0.02 \\
Second day afternoon & -49.01 & 3.99 & 0.54 \\
Third day morning & 123.46 & 4.35 & 0.96 \\
Third day afternoon & -56.60 & 4.55 & 0.39 \\
\hline
\end{tabular}

